Review

\title{
Chemical Coagulation/Flocculation Processes for Removal of Phenolic Compounds from Olive Mill Wastewater: A Comprehensive Review
}

\author{
${ }^{1}$ Mounia Achak, ${ }^{1,3}$ Fatima Elayadi and ${ }^{1,2}$ Wafaa Boumya \\ ${ }^{1}$ Science Engineer Laboratory for Energy (LabSIPE), \\ National School of Applied Sciences, Chouaïb Doukkali University, El Jadida, Morocco \\ ${ }^{2}$ Chemistry and Mathematical Modeling Laboratory, \\ Faculty polydisciplinary, Hassan First University, Khouribga, Morocco \\ ${ }^{3}$ Laboratory of Plant Biotechnology, Ecology and Valorization of Ecosystems, \\ Sciences Faculty, Chouaïb Doukkali University, El Jadida, Morocco
}

Article history

Received: 09-01-2019

Revised: 04-03-2019

Accepted: 27-03-2019

\section{Corresponding Author:}

Mounia Achak

Science Engineer Laboratory for

Energy (LabSIPE), National

School of Applied Sciences,

Chouaïb Doukkali University, El

Jadida, Morocco

Tel: +212661474231

Fax: +212523394915

Email: achak_mounia@yahoo.fr

\begin{abstract}
Olive oil extraction processes generate three phases: Olive oil, solid residue (pomace) and aqueous liquor Olive Mill Wastewater (OMW). OMW causes serious environmental deteriorations such as coloring of natural waters, alteration of soil quality, phytotoxicity and odor nuisance. The direct discharge of this effluent into the soil bring various negative effects on the environment, due to its high load of organic matter and phenolic compounds. Coagulation, flocculation and their combination processes are among the most applied processes for wastewater treatment. The application of coagulation technique using mineral and inorganic polymeric coagulants and acid cracking is not always effective to reduce COD and phenolic compounds from OMW except lime. Although direct flocculation is a low treatment cost, use less chemical and produce less sludge, the efficiency of COD and phenolic compounds removal remain very low. Coagulationflocculation process is developed in order to enhance the removal efficiency of organic matter from OMW by optimizing the operating conditions. However, many studies showed that the combination of various cationic organic coagulant and flocculant agents did not show any significant decrease of COD and phenolic compounds except for lime combination. In the present review, recent research studies dealing with the application of coagulation/flocculation for removal of phenolic compounds and COD from OMW are presented and compared. Furthermore, the main factors that influence the selection between coagulation, direct flocculation and coagulation-flocculation are presented and the principal removal mechanisms are discussed.
\end{abstract}

Keywords: Olive Mill Wastewater, Coagulation, Direct Flocculation, Coagulation-Flocculation, Mechanisms, Removal Efficiency

\section{Introduction}

The production of olive oil is not restricted to the Mediterranean Basin. Lately, it is also increasing in other countries like France, Serbia, Montenegro, Macedonia, Cyprus, Turkey, Israel, Jordan, USA, Australia and the Middle East. According to the reports of International
Olive Council (IOC), 3.17 million tons of olive oil were produced in the season 2015/16 (IOC, 2016). In that year, the highest volume of olive oil was produced in Spain $(1401600 \mathrm{t})$ followed by Italy $(474600 \mathrm{t})$, Greece $(320000 \mathrm{t})$, Turkey $(150000 \mathrm{t})$, Tunisia $(140000 \mathrm{t})$ and Morocco $(130000 \mathrm{t})$. However, according to the latest reports, 2.53 million tons of olive oil were produced 
globally in the year $2016 / 17$ with $20 \%$ reduction as compared to the previous year (IOC, 2017). In 2016/17 year, the highest amount of olive oil was produced in Spain $(1286600 \mathrm{t})$ followed by Greece $(195000 \mathrm{t})$, Italy $(182300 \mathrm{t})$, Turkey $(177000 \mathrm{t})$ and Morocco $(110000 \mathrm{t})$.

The IOC report for 2017 pretends an increase of olive oil world production in $2017 / 18$ at 2.9 million tons. The production can reach 1.8 million tons in the European Union (EU), 287000 tons in Turkey, 220000 tons in Tunisia and 140000 tons in Morocco.

Since 2008, Morocco has almost doubled its olive production to 1.5 million tons and created over 300,000 new jobs. According to the Moroccan Center for Export Promotion, there are 784,000 hectares of olive groves, 120,000 tons of olive oil and 90,000 tons of table olives produced annually. The country is the second-largest global exporter of table olives, exporting 64,000 tons of olives, as well as 17,000 tons of olive oil. Morocco plans to increase olive cultivation to an area of $1,220,000$ hectares, while production will increase to 2.5 million by 2020 according to the reports of Agriculture and Maritime Fisheries Moroccan Ministry (2015).

Although olive oil is a product of exceptional nutritional value, its production is associated with several adverse effects to the environment, mainly due to the formation a large amount of two by-products, a solid residue and an effluent known as Olive Mill Wastewater (OMW). Approximately 30 million $\mathrm{m}^{3}$ of OMW are produced annually in the Mediterranean area, characterized by a high pollutant load (Chiavola et al., 2014).

The straight discharge of OMW to the ground fields and superficial water bodies causes a various negative adverse effects on the environment, such as soil contamination, strong odor nuisance, hindrance of plants growth, underground leaks, water body pollution, as well as severe impacts to the aquatic fauna and to the ecological status. These negative effects are due to the presence of bio-refractory contaminants, including a wide variety of phenolic compounds, tannins, fatty acids and organohalogenated pollutants (Danellakis et al., 2011; Karaouzas et al., 2011; Martínez Nieto et al., 2011; Hodaifa et al., 2013; Ntougias et al., 2013).

\section{Processes for Olive Oil Extraction}

There are two main processes used by olive mill industry to produce olive oil: Discontinuous process (pressing) in traditional mills and continuous (centrifuging) process in modern units respectively (Fig. 1). The discontinuous process is the oldest and most widespread method for processing olive fruit to obtain olive oil. In this process, the olives are washed, crushed with stone rollers and kneaded with the addition of hot water. The resulting paste is spread onto fiber disks that are stacked on top of each other and then placed in the press in order to drain the oil. These disks were traditionally made of hemp or coconut fibers but they are now made of synthetic fibers for easier cleaning and maintenance. The press extraction sub-process yields a liquid waste (OMW) and a solid fraction called olive pomace (olive cake) containing olive pulp, skin, stone and water. Finally, olive oil is separated from the water by vertical centrifugation or decanting. This process has many advantages such as cheap equipment, technical simplicity, minimum mixing time and small volume of OMW produced (40 to $60 \mathrm{~L} / 100 \mathrm{~kg}$ olives) (Dermeche et al., 2013). However, it also has many disadvantages, such as process discontinuity, contamination of the oil diaphragms, high manpower costs and high load of OMW (Ayoub, 2006).

During the last 20 years, a significant technological progress has been made in olive oil extraction industry. Manufacturers of processing equipment have developed the centrifuge systems (three-phase and two-phase) in order to improve processing efficiency and quality of olive oil. Currently, the majority of traditional olive mills have been replaced by integral centrifuge systems (Torres and Maestri, 2006).

In the centrifuge process, a horizontal centrifuge allows continuous operation. The olive oil production is based on the differences in the density of the olive paste components. The three-phase decanters requires the addition of water to the system, which dilutes out watersoluble compounds and separates the paste into three fractions: A solid residue (olive cake) and two liquid phases (oil and OMW). This process has numerous advantages including, increased production, minimized labor cost, smaller space requirement, better quality of oil, improved process control and ease in automation. But also comes with disadvantages such as higher levels of water and energy consumption, a higher OMW output (80-120 L/100 kg olives) (Alburquerque et al., 2004) and more expensive installation (Roig et al., 2006). In order to reduce the volume of OMW, the two-phase extraction process was developed since 1992. In this type of centrifuge, very small amounts of water are added to dilute the olive paste. Using this method, the olive paste is separated into two phases: Olive oil and wet pomace. The wet pomace generated is a semi-solid by-product (a combination of olive husk and OMW) known as twopahse olive mill wastewater (TPOMW). The main advantage of this process is minimizing the high cost of wastewater handling and disposal. However, the resulting TPOMW (10 L/100 kg olives) is difficult to manage because its pollutant load is more become too wet and concentrated (Di Giovacchino, 1996). 


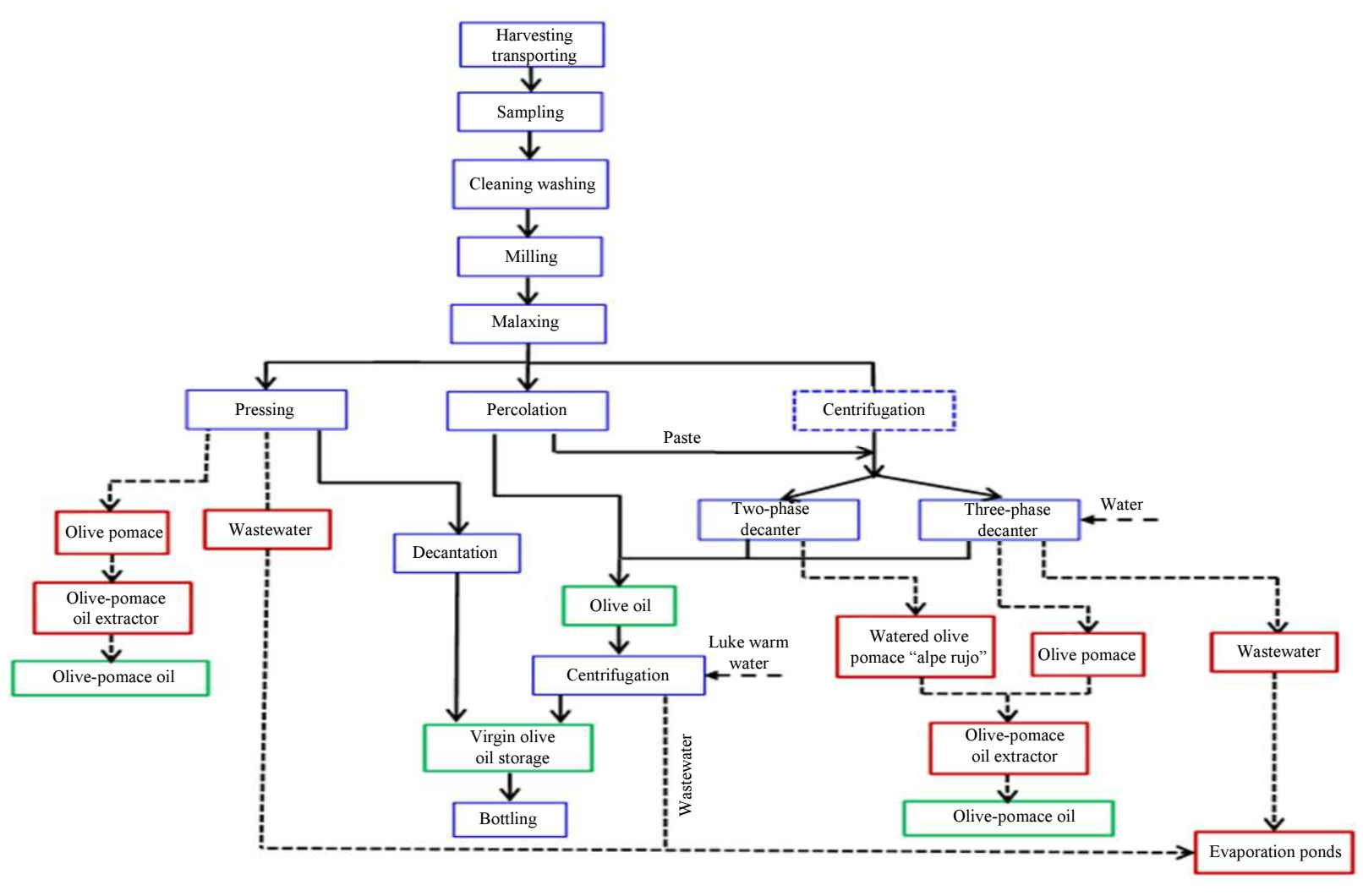

Fig. 1: Main processes of olive oil extraction

\section{OMW Characterization}

\section{Physico-Chemical Characteristics of OMW}

The physico-chemical composition of OMW is extremely variable as it depends on several factors such as the extraction process, storage time, climatic conditions and cultivation parameters, as well as the type, quality and maturity of the processed olives. OMW typically exhibit intense violet-dark colour, strong odour, considerable saline toxicity reflected by high electric conductivity values and very heavy organic pollutants load. According to McElhatton and Do Amaral (2011), OMW is composed of (88-94\%) water, (4-16\%) organic compounds and (0.4-2.5\%) mineral salts. In addition, OMW is known as recalcitrant effluent, which is characterized by an acidic $\mathrm{pH}$ (4-5.5). Table 1 presents a compilation of literature data on physic-chemical characteristics of different OMW according to its origin and olive oil extraction processes. As it can be seen, the $\mathrm{pH}$ of OMW is very acidic [3.50-6.00]. Assas et al. (2002) explains this high acidity by a self-oxidation reactions and polymerization of phenolic compounds. These compounds convert during the OMW storage before its acidity measured. These reactions result in a change in the initial color of OMW to a very dark black color. Nefzaoui (1991; Markus et al., 2015) also recorded a high value of $\mathrm{pH}$.
The use of this effluent for irrigation can damages soil, excepted calcareous soils where the equilibrium can be established (Nefzaoui, 1991). According to Table 1, it can be observed that the electrical conductivity of OMW varies from one system of trituration to another and it can take values ranging from 0.64 to $45.5 \mathrm{~ms} / \mathrm{cm}$ and some cases can reach $50 \mathrm{~ms} / \mathrm{cm}$ (Di Serio et al., 2008). This highest concentration of salt is due to salting practices for the conservation of olive before milling, in addition to the natural wealth of OMW of dissolved minerals (Ouzounidou et al., 2010). OWW is commonly composed of high concentration of Total Suspended Solids (TSS) (peel, pulp, ground, branches and leaves debris) derived from the washing procedure of the olive fruit. Alaoui Slimani et al. (2016) accorded this high concentration to the bad separation of OMW from the olive pomace. According to Guadalquivir Hydrographical Confederation 2006-2014, the standard limits of TSS for discharge on suitable soils should not exceed $500 \mathrm{mg} / \mathrm{L}$. for this reason Zanjari and Nejmeddine (2001) indicated that the high TSS content (over $20 \mathrm{~g} / \mathrm{L}$ ), may affect the soil porosity by reducing large pores $(\mathrm{r}>10 \mu \mathrm{m})$ and increasing small pores $(\mathrm{r}<0.1 \mu \mathrm{m})$. On the other hand, Barbera et al. (2013) reported that the high quantity of TSS might cause plugging in irrigation systems that will lead to additional costs for farms. Concerning organic matter, OMW has high concentrations of recalcitrant 
compounds such as lignins and tannins, phenolic compounds, lipids, protein, long-chain fatty acids and simple and complex sugars (Barbera et al., 2013). The most commonly found sugars in decreasing quantities are fructose, mannose, glucose, sacharose, sucrose and some pentoses (Niaounakis and Halvadakis, 2004).

In addition, OMW presents a strong organic content $\mathrm{BOD}_{5}[0.80-68.71 \mathrm{~g} / \mathrm{L}]$ (in some cases up to $220 \mathrm{~g} / \mathrm{L}$ ) and COD [4.00-356.11 g/L], both are considered such as a global pollution parameters. On the other hand, these parameters give a good idea of OMW biodegradability. Actually, COD represents the total organic matter in $\mathrm{OMW}$ and $\mathrm{BOD}_{5}$ represents only biodegradable fraction in it. If all the organic matter of OMW were biodegradable, $\mathrm{BOD}_{5}=\mathrm{COD}$. Many organic molecules present in the OMW are not or very slowly biodegradable such as, the polyphenolic compounds $\left(\mathrm{BOD}_{5}<\mathrm{COD}\right) . \quad \mathrm{BOD}_{5} / \mathrm{COD}$ allows getting a realistic idea of the effluent biodegradability and choosing an efficient method of treatment (biological and/or physico-chemical treatment).

The total solids (TS) represent all mineral and organic particles in OMW. High TS concentrations [0.1$197.00 \mathrm{~g} / \mathrm{L}]$ can be regarded as a form of pollution (Alba, 1994). According to Aktas et al. (2001), the TS content of centrifugation process is approximately two times more than the one in traditional process and it is in suspended form. This behavior is probably due to use of the cloth bags during the pressing process. OMW contains very significant amounts of mineral salts (Table 1 ), $80 \%$ is soluble (phosphates, chlorides and sulfates) and $20 \%$ is insoluble (carbonates and silicates). The most representative elements are potassium (47\%), carbonates (21\%), phosphate (14\%) and sodium (7\%) (Tsagaraki et $a l ., 2007)$. In the wastewater as OMW, phosphorus can be in the form of inorganic salts (Orthophosphates, polyphosphates) and in the form of organic compounds dissolved or attached to suspended solids. The high levels of these elements can lead to eutrophication in storage ponds. As shown in Table 1, the metal charge of OMW is very important, especially of iron, copper, zinc and magnesium (Sellami et al., 2008).

\section{Phenolic Content of OMW}

Phenolic compounds include many organic substances that all possess an aromatic ring with one or more substituted hydroxyl groups and a functional side-chain. Natural phenolic compounds include simple molecules, such as phenolic acids and highly polymerized compounds such as tannins. The phenolic compounds in olives are distributed between the olive oil, the solid phase pomace and the aqueous liquor wastewater (OMW). Only $2 \%$ of the total phenolic content of the olive fruit remains in the oil phase, while the rest is lost in the solid phase (approximately 45\%) and the greatest percent in the OMW (approximately 53\%) (Rodis et al., 2002). In the same line, McNamara et al. (2008) reported that phenols present in olive stone and pulp tend to be more soluble in the water phase than in oil.

Table 1: Physico-chemical characteristics of OMW given by several authors

\begin{tabular}{|c|c|c|c|c|c|c|}
\hline References & $\begin{array}{l}\text { Vlyssides et al. } \\
(2004)\end{array}$ & $\begin{array}{l}\text { Achak et al. } \\
(2009 \mathrm{~b})\end{array}$ & $\begin{array}{l}\text { Hodaifa et al. } \\
(2013)\end{array}$ & $\begin{array}{l}\text { Belaqziz et al. } \\
(2016)\end{array}$ & $\begin{array}{l}\text { Agabo García and } \\
\text { Hodaifa (2017) }\end{array}$ & Azzam (2018) \\
\hline OMW origin & Greece & Morocco & Spain & Morocco & Spain & Jordon \\
\hline Extraction process & Press & 3-phase & 2-phase & Press & 3-phase & 3-phase \\
\hline $\mathrm{pH}$ & 4.5 & 5.06 & $3.50-6.00$ & 4.72 & 5.38 & 5.4 \\
\hline $\mathrm{EC}(\mathrm{ms} / \mathrm{cm})$ & 18 & 6.85 & $1.50-2.50$ & 45.5 & 0.64 & 12.71 \\
\hline $\operatorname{COD}(g / L)$ & 158.18 & 70.22 & $4.00-16.0$ & 356.11 & 12.24 & 41.5 \\
\hline $\mathrm{Na}^{+}(\mathrm{g} / \mathrm{L})$ & 0.4 & 0.46 & n.d. & 2.06 & 0.005 & 0.006 \\
\hline $\mathrm{K}^{+}(\mathrm{g} / \mathrm{L})$ & 3.77 & 2.11 & n.d. & 2.45 & 0.02 & 0.02 \\
\hline $\mathrm{Ca}^{2+}(\mathrm{g} / \mathrm{L})$ & 0.38 & 2.11 & n.d. & 0.24 & 0.005 & 0.002 \\
\hline $\mathrm{Mg}^{2+}(\mathrm{g} / \mathrm{L})$ & 0.07 & n.d. & n.d. & n.d. & n.d. & 0.001 \\
\hline $\mathrm{Fe}(\mathrm{mg} / \mathrm{L})$ & 48 & n.d. & n.d. & n.d. & 23.8 & Negligible \\
\hline $\mathrm{Cu}(\mathrm{mg} / \mathrm{L})$ & 10.5 & n.d. & n.d. & n.d. & n.d. & 0.94 \\
\hline $\mathrm{Mn}(\mathrm{mg} / \mathrm{L})$ & 18.24 & n.d. & n.d. & n.d & n.d. & n.d. \\
\hline $\mathrm{Cl}^{-}(\mathrm{g} / \mathrm{L})$ & 0.21 & 1.42 & n.d. & 4.62 & 0.05 & n.d. \\
\hline $\mathrm{TP}(\mathrm{g} / \mathrm{L})$ & 17.15 & 13.45 & $0.10-1.00$ & 9.37 & 0.13 & 0.35 \\
\hline $\mathrm{PO}_{4}{ }^{3-}(\mathrm{g} / \mathrm{L})$ & 0.87 & 0.36 & n.d. & 2.77 & n.d. & n.d. \\
\hline TSS (g/L) & 4.51 & 2.07 & $2.00-7.00$ & 71 & 0.07 & 0.02 \\
\hline $\mathrm{TS}(\mathrm{g} / \mathrm{L})$ & 99.7 & 20.4 & n.d. & 197 & 0.1 & n.d. \\
\hline MM (g/L) & 9.69 & 5.29 & n.d. & 88 & 0.04 & n.d. \\
\hline TNK $(g / L)$ & 1.15 & 1.96 & n.d. & n.d. & 0.04 & n.d. \\
\hline $\mathrm{DBO}_{5}(\mathrm{~g} / \mathrm{L})$ & 68.71 & 16.74 & $0.80-6.00$ & n.d. & 0.35 & n.d. \\
\hline Sugar (g/L) & 25.86 & 0.12 & n.d. & n.d. & n.d. & n.d. \\
\hline proteins $(\mathrm{g} / \mathrm{L})$ & 28.3 & n.d. & n.d. & n.d. & n.d. & n.d. \\
\hline Density (g/L) & 1.05 & 1.1 & n.d. & n.d. & n.d. & n.d. \\
\hline
\end{tabular}

Chemical Oxygen Demand (COD), Total Phenols (TP), Total Suspended Solids (TSS), Total Solids (TS), Minerals Matters (MM), Total Nitrogen Kjeldahl (TNK), Biological Oxygen Demand (BOD 5 ), not determined (n.d.) 
Table 2: Most abundant phenolic compounds detected in OMW (DellaGreca et al., 2004; Obeid et al., 2007; Rodríguez et al., 2009)

\begin{tabular}{|c|c|c|c|}
\hline \multirow{3}{*}{$\begin{array}{l}\text { Compound name } \\
\text { Cinnamic acid and derivatives }\end{array}$} & MW (g/mol) & Substituent & \multirow[t]{2}{*}{ Structure } \\
\hline & & & \\
\hline & 148 & - & \\
\hline p-coumaric acid & 164 & $4-\mathrm{OH}$ & \\
\hline Caffeic acid & 180 & $3,4-\mathrm{OH}$ & 3 \\
\hline Ferulic acid & 194 & $3-\mathrm{OCH}_{3}, 4-\mathrm{OH}$ & \\
\hline Synaptic acid & 224 & $3,5-\mathrm{OCH}_{3}, 4-\mathrm{OH}$ & \\
\hline \multicolumn{4}{|l|}{ Benzoic acid and derivatives } \\
\hline Benzoic acid & 122 & - & \\
\hline p-Hydroxybenzoic acid & 138 & $4-\mathrm{OH}$ & \\
\hline Protocatechuic acid & 154 & 3-OH, 4-OH & \\
\hline Vanillic acid & 168 & $3-\mathrm{OCH}_{3}, 4-\mathrm{OH}$ & \\
\hline Veratric acid & 182 & $3-\mathrm{OCH}_{3}, 4-\mathrm{OCH}_{3}$ & \\
\hline Gallic acid & 170 & $3,4,5-\mathrm{OH}$ & \\
\hline Syringic acid & 198 & 3,5-OCH3, 4-OH & \\
\hline \multicolumn{4}{|l|}{ Tyrosol and derivatives } \\
\hline Tyrosol & 138 & 4-OH, R-H & \\
\hline Hydroxytyrosol & 154 & 3,4-OH, R-H & \\
\hline 3,4-Dihydroxyphenylglycol & 170 & 3,4-OH, R-OH & \\
\hline \multicolumn{3}{|c|}{ Other phenol acids and derivatives } & 5 \\
\hline p-Hydroxyphenylacetic acid & 152 & $4-\mathrm{OH}$ & \\
\hline 3,4-Dihydroxyphenylacetic acid & 168 & $3,4-\mathrm{OH}$ & \\
\hline \multicolumn{4}{|l|}{ Flavonoids } \\
\hline Apigenin & 270 & $\mathrm{R}_{1}-\mathrm{H}, \mathrm{R}_{2}-\mathrm{H}$ & \\
\hline Luteolin & 286 & $\mathrm{R}_{1}-\mathrm{H}, \mathrm{R}_{2}-\mathrm{OH}$ & \\
\hline Quercetin & 302 & $\mathrm{R}_{1}-\mathrm{OH}, \mathrm{R}_{2}-\mathrm{OH}$ & \\
\hline Rutin & 610 & $\mathrm{R}_{1}-\mathrm{OH}, \mathrm{R}_{2}$-O-rutinose & \\
\hline \multicolumn{4}{|l|}{ Ecoiridoids } \\
\hline Oleuropein & 540 & R-O-glucose & \\
\hline Oleuropein aglycone & 378 & $\mathrm{R}-\mathrm{OH}$ & \\
\hline
\end{tabular}

Phenolic compounds can be grouped into various classes according to the structural characteristics of their carbon skeletons. As shown in Table 2, the main classes are:

- Derivatives of cinnamic acid (p-coumaric acid, caffeic acid, ferulic acide and synaptic acid)

- Derivatives of benzoic acid (p-hydroxybenzoic acid, protocatechuic, vanillic acid, veratric acid, gallic acid and syringic acid)

Lesage-Meessen et al. (2001; Alburquerque et al., 2004) showed that the phenolic profiles (caffeic acid, ferulic acid, p-coumaric acid, vanillic acid), identified by HPLC, are similar for two-phase or three-phase oil extraction processes, but the amounts of individual phenols, with the exception of vanillic acid, were higher for the two- phase system.

Derivatives of tyrosol (hydroxytyrosol and 3,4dihydroxyphenylacetic acid).

Leouifoudi et al. (2014) reported that the tyrosol and hydroxytyrosol are the main phenolic compounds found in OMW. Other phenolic compounds were also detected in OMW (Table 2), such as flavonoids (apigenin, luteolin, quercetin, rutin) and secroiridois (aglycone, oleuropein). Oleuropein is the most abundant phenolic compound in olive leaves and fruits and is responsible for the characteristic bitterness of olive fruit (SolerRivas et al., 2000). It is degraded gradually into elenolic acid and hydroxytyrosol by an esterase during the mechanical olive oil extraction process (Visioli et al., 2002). For this reason, hydroxytyrosol is considered as the most abundant phenol in OMW.

The phenolic content of the OMW is reported to fluctuate between 0.1-17.15 g/L, depending on various factors; olive cultivate, soil composition, ripeness of the fruit, storage condition prior to extraction and processing techniques. The climate and the geographical conditions have also been shown to alter phenolic content in OMW (Dermeche et al., 2013; Obied et al., 2005). Several authors (Quaratino et al., 2007; Hanifi and El Hadrami, 2008; Doula et al., 2012; Hanafi et al., 2013; Papadaki et al., 2018) reported that phenolics are responsible of the high toxicity of OMW and they are the 
main compounds that suppress germination and may also lead to significant reductions in root growth. Moreover, the typical brownish-C color of this effluent has been explained by the presence of polymeric phenols that display a lignin-like structure and constitute its most resistant fraction (Hamdi, 1993).

From this analysis, it is clear that the wastewater streams produced during olive oil production have considerable different characteristics that, along with the final quality requirements, should be taken into account when selecting the most appropriate treatment strategy.

\section{Important Strategies for OMW Treatment}

OMW is characterized by a strong offensive smell and a high degree of organic matter mainly comprising phenolic compounds, polysaccharides, sugars, proteins, nitrogenous organics, tannins and fats. Moreover, OMW has been found to be very phytotoxic and it also inhibits microbial activity because of the biocidal activity of the polyphenols contained (Roig et al., 2006; Khoufi et al., 2009; Yalılı Kılıç et al., 2013; Amor et al., 2015). For these reasons, the management and treatment of OMW have been considered as the main goal of the majority of research studies in this field.

The most common practice for the management of OMW includes the use of evaporation ponds and direct spreading in landfills and/or on soil. While evaporation ponds offer a good way of reducing the liquid portion of this effluent, they do not contribute to the reduction of its toxicity. They simultaneously impart an odor problem to the areas where such waste is stored and cause pollutant infiltration to groundwater and insect proliferation (Jarboui et al., 2010; Michael et al., 2014). Moreover, the direct spreading of raw OMW on agricultural lands has been thoroughly investigated during the last decades (Morisot, 1979; Rozzi and Malpeli, 1996; Marques, 2001; Di Bene et al., 2013; Barbera et al., 2014; Chaari et al., 2015; Belaqziz et al., 2016; Keren et al., 2017; Aharonov-Nadborny et al., 2018) and it has been proved that it represents an alternative inexpensive technique compared to filtration-percolation (Achak et al., 2009b) and coagulation-flocculation (Achak et al., 2008). Many researchers have studied the result of the OMW application on soil and crops (Mekki et al., 2006; Di Bene et al., 2013; Belaqziz et al., 2016) and they found that it exerts beneficial and negative effects. Beneficial effects are related to its high nutrient concentration, especially potassium and its potential to mobilize soil ions (Roig et al., 2006). Negative effects are associated with its high mineral salt content, low $\mathrm{pH}$ and the presence of phytotoxic compounds, especially polyphenols (Roig et al., 2006). Therefore, excessive application into the soil may exceed the toxicity tolerance of soil microorganisms.

In recent years, many other management options have been employed to reduce OMW phytotoxicity in order to reuse it for agricultural purposes (El-Abbassi et al., 2011) and to make it suitable to be treated in conventional treatment facilities (Dhaouadi and Marrot, 2008). The main management options proposed can be classified as: (i) Physical processes (e.g., evaporation, distillation, combustion, centrifugation, filtration, pyrolysis, etc.), (ii) membrane filtration and separation processes (e.g., microfiltration-MF, ultrafiltration-UF, nanofiltration-NF, reverce osmosis-RO, etc.), (iii) oxidation and advanced oxidation processes (e.g., ozonation, photo-Fenton oxidation, $\mathrm{TiO}_{2}$ photocatalysis, electrochemical oxidation, wet air oxidation, etc.), (iv) biological processes (e.g., aerobic active sludge, anaerobic digestion, etc.) and (vi) physic-chemical processes (e.g., adsorption, electrocoagulation, coagulation-flocculation, etc.).

Physical processes involve the concentration of organic and inorganic contents of OMW by evaporation of the water. The natural evaporation of OMW in ambient air with the use of solar energy in evaporation ponds or storage lakes (lagoons) has much lower energy costs and it is a simple technique (Jarboui et al., 2009). In the hot period of the year, OMW is collected and stored in ponds where it undergoes natural evaporation until becoming completely dry. However, the large area needed, bad odor due to the anaerobic fermentation of the waste, infiltration and proliferation are the negative properties of evaporation (Roig et al., 2006). Several distillation processes, which are already used in desalination and in the chemical and food industry, have been tested such as, vacuum, multiple effect and flash evaporation (Nitro-Atomizer, 1992; Leonzio, 2017). According to Niaounakis and Halvadakis (2004), although these processes are claimed to reduce significantly the volume of waste $(70-75 \%)$ great differences exist in bibliography concerning their effectiveness, because it depends on many factors such as extraction process, olive ripening and especially storage time of the waste. The main drawback of distillation processes is related to the post-treatment and disposal of the produced emission. In addition, the distillate output and condensate produced contain a high level of volatile compounds such as alchools, polyphenols and volatile acids. These compounds make the condensate too acidic ( $\mathrm{pH} 4-4.5)$ and high values of $\operatorname{COD}(>3 \mathrm{~g} / \mathrm{L})$ and $\operatorname{BOD}(>4 \mathrm{~g} / \mathrm{L})$ (Niaounakis and Halvadakis, 2004). Combustion and pyrolysis processes have the advantages of reducing the volume of waste and providing the possibility of energy recovery, but they are radical and destructive techniques that eliminate any possibility of further use of OMW and they require expensive facilities and entail possible emission into the atmosphere of toxic substances. Centrifugation and filtration increase the $\mathrm{pH}$ and conductivity of the effluents and remove organic matter through phase separation and exclusion respectively. As shown, the simple physical processes are not able, if applied alone, 
to reduce the organic matter and the toxicity of OMW to acceptable limits (Paraskeva and Diamadopoulos, 2006). Several researchers have proposed the combination of physical processes with other technologies. Usually a combination of physical processes or often a combination of physical processes coupled with coagulation/flocculation (Achak et al., 2008) or adsorption technologies leads to more efficient organic matter removal. Application of sedimentation followed by centrifugation and then filtration showed that, after centrifugation, COD was reduced by $21 \%$ and BOD by 15\% (Al-Malah et al., 2000). Additional filtration did not remove any COD, but a further $16 \%$ reduction in $\mathrm{BOD}$ was observed. The combination of centrifugation and ultrafiltration provided the reduction of pollution caused by the wastes and the selective separation of some useful products that are present (fats, sugars, polyphenols, etc.). in contrast, approximately $90 \%$ COD reduction was achieved (Turano et al., 2002). The combination of electrocoagulation and sedimentation proposed by Khoufi et al. (2007) allowed a COD reduction and decoloration of about 43 and $90 \%$ respectively.

Membrane processes, such as MF, UF, NF and RO, have been proposed to obtain effluent streams from OMW of acceptable quality for safe discharge in the environment, tree or land irrigation, or even for recycling and reuse in the olive mill facilities (Cassano et al., 2011; Ochando-Pulido et al., 2014; Zagklis et al., 2015; Sanches et al., 2016; Kontos et al., 2016; 2018; Ioannou-Ttofa et al., 2017). Most of these studies indicated that membranes processes exhibit high selectivity values required to achieve high water quality standards. They are more cost-effective than other conventional processes, require less area and can replace several unit treatment processes by a single one. However, the implementation of membrane technologies in OMW treatment suffer from various drawbacks, such as the membrane fouling, the energy cost and the membrane replacement (Miguel and Pulido, 2016; Ioannou-Ttofa et al., 2017). In addition, the concentrate generated contains high levels of refractory organic pollutants and inorganic salts which needs further treatment before its disposal in the environment,

Advanced Oxidation Processes (AOPs) are based on the creation of very reactive species, such as hydroxyl radicals (HO). According to previous studies, several organic pollutants can be decomposed partially or totally into other less toxic and more degradable substances by oxidation based on UV light or other processes. Generally, only a small fraction of the radiant energy is absorbed by the organic molecules, causing decomposition of small percentage of the pollutant molecules. AOPs have been extensively studied for the OMW treatment through ozonation, photo-Fenton oxidation, $\mathrm{TiO}_{2}$ photocatalysis, electrochemical oxidation and wet air oxidation. Their efficiency was found to be significatif (Gernjak et al.,
2004; Canizares et al., 2007; 2009; Chatzisymeon et al., 2009; Mert et al., 2010; Belaid et al., 2013; Michael et al., 2014; Ioannou-Ttofa et al., 2017; Davididou et al., 2018). Although, AOPs manage a great COD reduction, but their operating costs are considerably high. It could be said that chemical oxidation emerges as a suitable alternative, when biological degradation is not applicable.

Biological processes use microorganisms to degrade the chemicals present in OMW. They are divided into aerobic and anaerobic processes according to the type of the microflora used (McElhatton and Do Amaral, 2011). Most aerobic biological processes, technologies and microorganisms have been tested for the treatment of OMW, aimed at reducing organic load, dark color and toxicity of the effluent (Beltrán-Heredia et al., 2001; Roig et al., 2006; Taccari and Ciani, 2011; Pelendridou et al., 2014; Tekerlekopoulou et al., 2017). In general, aerobic bacteria appeared to be very effective against some low-molecular-mass phenolic compounds due to their fast process kinetic and high removal rates, but they are relatively ineffective against the more complex polyphenolics responsible for the dark coloration of OMW (Ragazzi and Veronese, 1973; Olori et al., 1990; Morillo et al., 2009; Ioannou-Ttofa et al., 2017). In addition, aerobic processes can operate efficiently only if the concentration of the feed is relatively low ( $1 \mathrm{~g}$ $\mathrm{COD} / \mathrm{L}$ ). High concentration can be tolerated only if the plant operates at a long hydraulic retention time and/or with high recycle ration (Rozzi and Malpeli, 1996; Tsagaraki et al., 2007). Also, the aerobic treatment of concentrated wastewater yields huge volume of excess secondary aerobic processes to reach the required removal efficiency such as phenolic compounds and lipids. For all the above reasons, aerobic processes are unsuitable for direct and efficient treatment of OMW. Many researchers suggest that they can be used as pretreatment or posttreatment steps to increase the efficiency of the main treatment processes used (Azbar et al., 2008; Justino et al., 2009; Pelendridou et al., 2014; González-González and Cuadros, 2015; Tekerlekopoulou et al., 2017). Anaerobic treatment consists of a series of microbiological processes that convert organic compounds into biogas that can be used for energy production. However, OMW characteristics such as, the acidic $\mathrm{pH}$, low alkalinity and low nitrogen content, as well the presence of lipidic and phenolic fractions, make this wastewater potentially toxic for anaerobic treatments (Boari et al., 1984; Hamdi, 1991a; 1991b; Angelidaki and Ahring, 1992; Beccari et al., 1998; Beltrán-Heredia et al., 2001; Marques, 2001; Sampaio et al., 2011). Therefore, some form of pretreatment and post treatment to eliminate phenolic compounds from OMW, apart from simple dilution, is usually necessary in order to reduce its toxicity and to permit the occurrence of microbial fermentation. In this regard, many authors directed their attention to a more promising alternative such as, co- 
digestion of OMW with other substrate like agrolivestock (Gonçalves et al., 2012a; 2012b; Sampaio et al., 2011; Kougias et al., 2014), physical chemical pretreatment (Filidei et al., 2003; Ginos et al., 2006; Ruggeri et al., 2015) and Fenton's reagent process (Amor et al., 2015; Maamir et al., 2017).

Various physico-chemical processes such as adsorption, electrocoagulation and coagulation/flocculation have also been employed for the OMW treatment. Adsorption has been found to be superior to other techniques for water reuse in terms of initial cost, flexibility and simplicity of design, ease of operation and insensitivity to toxic pollutants (Al-Malah et al., 2000; Zümriye and Jülide, 2001; Achak et al., 2009a; Frascari et al., 2016; Yangui and Abderrabba, 2018; Azzam, 2018). Adsorption also does not lead to the harmful substances and the organic sorbents can be used as fuel for power generation or as ferment substrate (Ahmad et al., 2011). The most popular and widely used adsorbent material for treatment of OMW is activated carbon due to their excellent adsorption abilities for organic pollutants (Galiatsatou et al., 2002; Azzam et al., 2004; Aliakbarian et al., 2015; Yangui and Abderrabba, 2018). In fact, many researchers have shown that activated carbon is an effective adsorbent for organic compounds removal, especially for phenolic compounds. However, its high initial cost and the need for a costly regeneration system make it less economically viable as an adsorbent (Babel and Kurniawan, 2003; Aktas and Cecen, 2007). Due to these facts, the search for a low cost and easily available adsorbent has led many investigators to search more economic and efficient techniques to use agricultural waste origin, along with industrial by-products as adsorbents (banana pith, orange peel, wheat straw, sawdust, powdered waste sludge, wheat shells, wheat bran and hen feathers). Many of these adsorbents have been tested and proposed for phenolic compounds removal (Sathishkumar et al., 2008; Achak et al., 2009a; 2014; Pathak et al., 2015; Ali and Saeed, 2015; Kong et al., 2016; Gupta and Gapta, 2016; Ingole et al., 2017). Coagulation/flocculation processes have also been employed in OMW treatment due to its simplicity, effectiveness and low energy consumption (Kissi, 2002; Jaouani et al., 2005; Achak et al., 2008; Michael et al., 2014; Enaime et al., 2018). Additional agent coagulants are used in these processes in order to destabilize the suspended and colloidal matter of OMW and form an insoluble solid that can be removed easily from the waste. Destabilization of these colloids can be achieved either by reducing or increasing $\mathrm{pH}$ (neutralization) or by the addition of a precipitate-inducing agent (precipitation/occulation). The effectiveness of coagulation process depends on the coagulating agent used, the dosage, the solution $\mathrm{pH}$, the presence of divalent cations and destabilizing anions such as bicarbonate, chloride and sulfate ions (Duan and Gregory, 2003; Lin and Lee, 2013) and the nature of the organic compound present in OMW (Dominguez et al., 2007). In generally, coagulation process is effective in removing high molecular weight organics (complex phenolic compounds), but less so in removing smaller molecular weight fractions (Nissinen et al., 2001). Flocculation process is usually more effective with higher molecular weight polymers. Adding excessive amount of polymer results in entire particle surface becoming coated with polymer, such that no sites are available to 'bridge' with other particles (Ebeling et al., 2006; Sarika et al., 2005). The flocs structure may differ as a function of physical-chemical conditions, as the flocs formed at the lower $\mathrm{pH}$ and dose are reported to be denser and less porous than those formed at higher $\mathrm{pH}$ and dose (Guigui et al., 2002). In order to increase the effectiveness of elimination of suspended particles and insoluble substances from OMW, the combined coagulation and flocculation processes has also been studied (Ginos et al., 2006; Chong, 2012; Iakovides et al., 2014; Hattab and Bagane, 2016; Enaime et al., 2018). Despite the simplicity, effectiveness, low energy consumption and efficiency of the coagulation, flocculation and their combination, these techniques still exhibit several disadvantages such as the need for $\mathrm{pH}$ adjustment before or after treatment, the sensitivity to temperature changes, the need for higher dosages, the sensitivity to OMW characteristics and composition, as well as the excessive sludge produced. To the best of our knowledge, there were few works in the literature concerning studies of phytotoxicity from sludge through the coagulation/flocculation process alone. From the above considerations, it can be concluded that the coagulation/flocculation treatment of OMW cannot been achieved without combination with another treatment process in which to further degrade the organic compounds to lower level. Sarika et al. (2005) studied the pretreatment of OMW by flocculation with cationic and anionic polyelectrolytes. The majority of the tested flocculants completely removed the TSS and reduced considerably the COD and the $\mathrm{BOD}_{5}$. In another study, combination of coagulation, acid cracking and Fentonlike process could result the phytotoxicity of final OMW to decrease (Yazdanbakhsh et al., 2015). Stoller and Chianese (2006a) proposed a treatment process comprising an initial coagulation $\square$ flocculation with aluminium sulphate or aluminium hydroxide, followed by batch UF and NF in series with composite thin $\square$ film spiral-wound membranes. The two pretreatment processes yielded similar $\mathrm{COD}$ and $\mathrm{BOD}_{5}$ rejection efficiencies. Alver et al. (2015) applied coagulation with $\mathrm{FeSO}_{4}, 7 \mathrm{H}_{2} \mathrm{O}$ on three-phase OMW, observed a COD abatement equal to $51.4 \%$, as well as $38.6 \%$ of Total Oxygen Carbon (TOC) and $52.1 \%$ of total nitrogen removal. According to Rizzo et al. (2008), the reclamation of OMW by coagulation with a natural organic coagulant, chitosan, followed by advanced oxidation processes including Photocatalysis (PC), 
Fenton (F) or photo-Fenton (PF) has been studied. The optimum removal of TSS (81\%) was achieved by chitosan coagulation at a $\mathrm{pH}$ value of 4.3 upon $400 \mathrm{mg} / \mathrm{L}$ coagulant dose. In a recent study, Enaime et al. (2018) investigated a new combined process, comprising filtration of raw OMW on two successive Olive Stone (OS) filters followed by a coagulation-flocculation. The results showed that the use of OS filter leads to a higher removal of TSS $(82.5 \%)$ and fatty matter $(73.8 \%)$ from the raw OMW and a depletion of total phenolic compounds (11.3\%) and COD (23.2\%).

\section{Removal of Phenolic Compounds from OMW by Coagulation Process}

The coagulation process is a very important step in wastewater treatment, which is widely used, due to its simplicity and cost-effectiveness. Basically, coagulation is a physico-chemical process that facilities the destabilization of fine particles (colloids) from wastewater to form a floc that can be easily filtered. This destabilization phenomenon includes various mechanisms such as charge neutralization, entrapment, adsorption and complexation with the coagulant's metal ions into insoluble aggregates (Henderson et al., 2006). As far as phenolic compounds concerned and considering the olive oil extraction processes and origin of OMW, as well the structural characteristics of polyphenols carbon skeletons in term of number and position of acid functions $(\mathrm{COOH}$ and/or $\mathrm{OH})$ on the aromatic cycle, the combined removal mechanisms will substantially differ (Duan and Gregory, 2003; Crittenden et al., 2005). The result will therefore be a variable removal efficiency of coagulation and the formation of flocs with different sizes and structures (Jarvis et al., 2006; Sharp et al., 2006), which constitutes a serious challenge for the application of coagulation in the OMW treatment.

In addition, many researchers report that the efficiency of coagulation process to remove organic matter and phenolic compounds from OMW, depends mainly to coagulant's type and dosage, $\mathrm{pH}$, mixing condition and temperature on the one hand and phenolic compounds properties including particle size, charge and hydrophobicity (Korshin et al., 2009; Iakovides et al., $2014)$ and the presence of anionic $\left(\mathrm{PO}_{4}{ }^{3-}, \mathrm{SO}_{4}{ }^{3-}, \mathrm{Cl}^{-}\right)$and cationic $\left(\mathrm{Ca}^{2+}, \mathrm{Mg}^{2+}, \mathrm{Na}^{2+}\right)$ minerals (Lin and Lee, 2013; Hecini and Achour, 2014), on the other hand.

\section{Inorganic Metal Coagulant}

\section{Effect of Coagulant Dosage}

The conventional chemicals that are widely applied in OMW treatment, are mineral coagulants based on aluminum and iron. The aluminum coagulants include aluminum sulfate, aluminum chloride and sodium aluminate. The iron coagulants include ferric sulfate, ferrous sulfate and ferric chloride (Bahadori et al., 2013). In some cases, a combination of dual metal coagulants is also applied (Achak et al., 2008). The addition of these cationic coagulants results in colloidal destabilization, as they specifically interact with and neutralize the negatively charged colloids. Recently, considerable interest and attention have been paid to preparing pre-hydrolysed metalion coagulants (inorganic polymers), based on either aluminum (poly-aluminum chloride) (Hu et al., 2015; Wang et al., 2017), or ferric iron (polyferric sulfate) (Zouboulis et al., 2008) and/or, a mixed polymeric coagulant (polyaluminum-iron-sulfate) (Zhu et al., 2005). These have been shown to perform better in some cases, in comparison with conventional coagulants such as aluminum sulfate or ferric sulfate (Jiang and Graham, 1996). Several studies of metal/polymer for removal of organic matter and phenolic compounds from OMW are reported in this review.

Achak et al. (2008) addressed the treatment of OMW with aluminum sulphate. The results showed a slight removal of phenolic compounds (32\%) and Chemical Oxygen Demand (COD 33\%) at optimum dosage (1.5 g/L) without correction of $\mathrm{pH}(\mathrm{pH}=4.55)$. These results were in agreement with Sbai and Loukili (2015) who concluded that at the same conditions of $\mathrm{pH}$ and dosage, the removal of phenolic compounds and COD from diluted OMW (10\% $\mathrm{v} / \mathrm{v}$ ) did not exceed $32 \%$ and $42 \%$ respectively (Table 3 ). Kissi et al. (2001) also observed that the application of 1.9 $\mathrm{g} / \mathrm{L}$ of aluminum sulphate and $2.72 \mathrm{~g} / \mathrm{L}$ of ferric chloride at $\mathrm{pH}$ solution (4.20) allowed only $18 \%$ and $14 \%$ of phenolic compounds reduction and $35 \%$ and $30 \%$ of COD reduction respectively. In another study, the use of acid cracking ( 9.5 $\mathrm{g} / \mathrm{L}$ ) as coagulant at acidic $\mathrm{pH} 2$ showed a low removal of phenolic compounds (37\%) and COD (46\%) (Mert et al., 2010). In a similar line, Ginos et al. (2006) tested the efficiency of various inorganic coagulants, involving magnesium sulphate, ferrous sulphate and ferric chloride applied to OMW, in term of organic matter and phenolic compounds reduction. Despite the variation of coagulants and their concentrations (1-4 g/L), the results showed an ineffectiveness removal of these compounds (Table 3). Ginos et al. (2006) showed that the application of $1 \mathrm{~g} / \mathrm{L}$ of magnesium sulphate led to about only $8 \%$ and $38 \%$ of COD and phenolic compounds reduction respectively at the $\mathrm{pH}$ of original sample $(\mathrm{pH} 5.2)$. The authors observed that an increasing in the magnesium concentrations from 1 to $4 \mathrm{~g} / \mathrm{L}$ had practically no effect on organic matter removal. In addition, ferric chloride at $1 \mathrm{~g} / \mathrm{L}$ led to about $50 \%$ and $10 \%$ COD and phenolic compounds reduction, respectively; these values were reduced to $7 \%$ and $10 \%$, when ferric chloride increases to $2 \mathrm{~g} / \mathrm{L}$. while further increase to $3 \mathrm{~g} / \mathrm{L}$ gave no removal of organic compounds. Jaouani et al. (2005) also observed that the application of ferric chloride $(20 \mathrm{~g} / \mathrm{L})$ at solution $\mathrm{pH} 3.1$ allowed only $44 \%$ and $34 \%$ of phenolic compounds and DCO reduction respectively. The results obtained by Iakovides et al. (2014) showed that the removal of phenolic compounds from OMW with 
application of calcium chloride $(5 \mathrm{~g} / \mathrm{L})$ and magnesium chloride $(7 \mathrm{~g} / \mathrm{L})$ at solution $\mathrm{pH} 4.4$ did not exceed $10 \%$ and $8 \%$ respectively. According to these results, at the $\mathrm{pH}$ of initial solution (acidic $\mathrm{pH}$ ), the reduction of phenolic compounds and COD from OMW was very low regardless to the nature and dosage coagulants used.

Basically, the coagulation mechanism can be achieved with one, or a combination of the following mechanisms, after the addition of an inorganic coagulant agent (Duan and Gregory, 2003; Crittenden et al., 2005):

- Electrostatic coagulation

- Adsorptive coagulation

- Precipitation coagulation

In electrostatic coagulation, the positively charged metal coagulants approach to the negatively charged colloids via electrostatic interaction. In the diffusive layer around the colloid, the positively charged ions accumulate and destabilizing the colloid. In adsorptive coagulation, particles are adsorbed to the positively charged hydrolyses products (i.e., $\mathrm{Fe}(\mathrm{OH})_{2}{ }^{+}, \mathrm{Fe}(\mathrm{OH})^{2+}$ or $\left.\mathrm{Al}(\mathrm{OH})_{2}{ }^{+}, \mathrm{Al}(\mathrm{OH})^{2+}\right)$. These products mainly occur at low $\mathrm{pH}$ 5.5. The optimal $\mathrm{pH}$-range for adsorptive coagulation with iron salts is between 6 and 8 , the optimal $\mathrm{pH}$-range with aluminum salts is narrower and is about 7 . Adsorptive coagulation is a rapid process. Within one second, positively charged hydrolyses products are formed and are adsorbed to the negatively charged particles. Characteristics of adsorptive coagulation mechanism are that dosing is proportional to the removal of organic matter and that restabilization can occur after an overdose of coagulant. Indeed, the colloids will be positively charged and repulsion of the particles will take place. In precipitation coagulation or sweep coagulation, colloids are incorporated into neutral hydroxide $\left(\mathrm{Al}(\mathrm{OH})_{3}\right.$ or $\left.\left.\mathrm{Fe}(\mathrm{OH})_{3}\right)\right)$ flocs and precipitated. These metal hydroxide compounds are heavy, sticky and larger (Edwards and Amirtharajah, 1985; Lee et al., 2014).

In our case, the most probable mechanism for the removal of organic matter and phenolic compounds from OMW is electrostatic and adsorptive coagulation. This explanation is in accordance with the studies of Zhang et al. (2003; Bacha and Achour, 2015), who reported that at acidic $\mathrm{pH}(\mathrm{pH} 4)$, the coagulation mechanisms were ensured by mainly charge neutralization and complex reaction or chelate reaction between organic matter and dissolved aluminum species $\left(\mathrm{Al}(\mathrm{OH})_{2}{ }^{+}\right.$and $\left.\mathrm{Al}(\mathrm{OH})^{2+}\right)$ dominant at this $\mathrm{pH}$. In line with this observation, Achak et al. (2008) noticed that at acidic $\mathrm{pH}$, the low elimination of phenolic compounds from OMW could be attributed to the absence of the flocculating form of the coagulant such as $\mathrm{Al}(\mathrm{OH})_{3}$, which would confine the neutralized species.

Table 3: Selected research studies on the removal of COD and phenolic compounds from OMW by coagulation process using metal coagulants and lime

\begin{tabular}{|c|c|c|c|c|c|c|c|c|}
\hline $\begin{array}{l}\text { OMW origin } \\
\text { Extraction process }\end{array}$ & Phenols (g/L) & $\mathrm{DCO}(\mathrm{g} / \mathrm{L})$ & Coagulant & $\operatorname{Dose}(g / L)$ & Phenols \% & $\mathrm{DCO} \%$ & $\mathrm{pH}$ & Ref \\
\hline Morocco & 1.42 & 71.56 & $\mathrm{Al}_{2} \mathrm{SO}_{4}$ & 1.5 & 23 & 33 & 4.55 & Achak et al. (2008) \\
\hline \multirow[t]{3}{*}{ (3-phase) } & & & $\mathrm{Al}_{2} \mathrm{SO}_{4}$ & 1.5 & 41 & 40 & 7 & \\
\hline & & & $\mathrm{Ca}(\mathrm{OH})_{2}$ & 20 & 75 & 43 & 12 & \\
\hline & & & $\mathrm{Al}_{2} \mathrm{SO}_{4}+\mathrm{Ca}(\mathrm{OH})_{2}$ & $1.5+20$ & 54 & 38 & 12 & \\
\hline $\begin{array}{l}\text { Morocco (3-phase } \\
\text { diluted } 10 \%)\end{array}$ & 0.89 & 27.16 & $\mathrm{Al}_{2} \mathrm{SO}_{4}$ & 1.9 & 22 & 42 & 4.5 & Sbai and Loukili (2015) \\
\hline Morocco & & & & & & & & \\
\hline \multirow[t]{3}{*}{ (3-phase) } & 4.2 & 122 & $\mathrm{Al}_{2} \mathrm{SO}_{4}$ & 2.72 & 18 & 35 & 4.2 & Kissi et al. (2001) \\
\hline & & & $\mathrm{FeCl}_{3}$ & 9.5 & 14 & 30 & 4.2 & \\
\hline & & & $\mathrm{Ca}(\mathrm{OH})_{2}$ & 4.12 & 37.5 & 53.6 & 7.5 & \\
\hline \multirow[t]{5}{*}{ Greece (n.d.) } & 3.5 & 61.1 & $\mathrm{FeCl}_{3}$ & 9.58 & 10 & 50 & 4.5 & Ginos et al. (2006) \\
\hline & & & $\mathrm{MgSO}_{4}$ & 7 & 38 & 8 & 5.2 & \\
\hline & & & $\mathrm{FeSO}_{4}$ & 5 & 20 & 10 & 4.6 & \\
\hline & & & PAC & 1 & $<10$ & $<10$ & 4.7 & \\
\hline & & & $\mathrm{Ca}(\mathrm{OH})_{2}$ & 60 & 67 & $<10$ & 11.4 & \\
\hline \multirow[t]{3}{*}{ Greece (3-phase) } & 1.9 & 40.9 & $\mathrm{FeCl}_{3}$ & n.d. & 10 & 43 & 1.5 & Iakovides et al. (2014) \\
\hline & & & $\mathrm{MgCl}_{2}$ & & 8 & 23 & 4.4 & \\
\hline & & & $\mathrm{CaCl}_{2}$ & & 10 & 25 & 4.4 & \\
\hline \multirow[t]{3}{*}{ Turkey (3-phase) } & 3.8 & 150 & $\mathrm{FeCl}_{3}$ & 2.5 & 26 & 57 & 7 & Gursoy-Haksevenler and \\
\hline & & & $\mathrm{Ca}(\mathrm{OH})_{2}$ & 6.7 & 30 & 56 & 11 & Arslan-Alaton (2014) \\
\hline & & & $\mathrm{Ca}(\mathrm{OH})_{2}+\mathrm{Ac}$ & 6.7 & 47 & 63 & 11 & Jaouani et al. (2005) \\
\hline \multirow[t]{2}{*}{ Iran (3-phase) } & 3.3 & 101 & $\mathrm{FeCl}_{3}$ & 20 & 44 & 34 & 3.1 & Yazdanbakhsh et al. \\
\hline & & & $\mathrm{CaO}$ & 20 & 71 & 37 & 12 & $(2015)$ \\
\hline \multirow[t]{2}{*}{ Iran (3-phase) } & n.d. & n.d. & $\mathrm{FeCl}_{3}$ & 3 & 91.3 & 91.2 & 6 & Aktas et al. (2001) \\
\hline & n.d. & n.d. & A.c $\mathrm{H}_{2} \mathrm{SO}_{4}$ & n.d. & 30 & 46 & 2 & \\
\hline Turkey (traditional) & 2.5 & 65.7 & $\mathrm{Ca}(\mathrm{OH})_{2}$ & 25 & 73 & 41 & 12 & Boukhoubza et al. (2009) \\
\hline Morocco (3-phase) & 2.08 & 120.3 & $\mathrm{Ca}(\mathrm{OH})_{2}$ & 40 & 73 & 20 & 12 & Lolos et al. (1994) \\
\hline Greece (3-phase) & 0.45 & 12.2 & $\mathrm{CaO}$ & 15 & 70 & 55 & 12 & Alaoui Slimani et al. (2016) \\
\hline \multirow[t]{2}{*}{ Morocco (3-phase) } & 2.1 & 64 & $\mathrm{CaO}$ & 7.5 & 65 & 40 & 10 & \\
\hline & & & $\mathrm{CaO}+\mathrm{FeCl}_{3}$ & $7.5+1.5$ & 75 & 58 & n.d. & \\
\hline
\end{tabular}

determined; PAC: Poly-aluminium chloride; A.c: Acid cracking 


\section{Effect of $p H$}

The most important parameter affecting the effectiveness of organic matter removal is $\mathrm{pH}$ (Qin et al., 2006). When the metal coagulant is added to the water, the hydrolysis reactions generate dissolved monomeric metal species and metal hydroxide precipitates and the distribution of those species depends on the $\mathrm{pH}$ of minimum solubility and total inorganic metal concentration. According to the bibliography, the hydrolyzing $\mathrm{pH}$ range for aluminum and iron (the most widely used) is between 5.5-7.7 and 4.5-7 respectively. If the $\mathrm{pH}$ is decreased below the optimal value, positively-charged dissolved $\mathrm{Al}$ or $\mathrm{Fe}$ species are generated $\left(\mathrm{Al} / \mathrm{Fe}(\mathrm{OH})_{2}{ }^{+}\right.$and $\left.\mathrm{Al} / \mathrm{Fe}(\mathrm{OH})^{2+}\right)$. In case of a $\mathrm{pH}$ increase above the optimum, more negativelycharged $\mathrm{Al} / \mathrm{Fe}$ species are formed $\left(\mathrm{Al} / \mathrm{Fe}(\mathrm{OH})_{4}{ }^{-}\right.$and $\left.\mathrm{Al} / \mathrm{Fe}(\mathrm{OH})_{5}{ }^{2-}\right)$ (Pernitsky and Edzwald, 2006). Noting that, away from the optimal range, especially at $\mathrm{pH} 3$ and 11 , the destabilization potential will be highly reduced and thus the small particles will not be able to aggregate into large flocs and the organic matter reduction will be very slight (Wang et al., 2016). At optimum $\mathrm{pH}$, the solubility is minimal and the main bulk of the coagulant is converted to solid floc particles, as shown below (Bratby, 2007):

Stable colloid+Inorganic metal coagulant $\rightarrow$ Unstable colloid Flocs (negatively-charged) ( positively-charged) (optimumpH)

According to Greenland (1971), the solid floc formation can be obtained by two main types of mechanisms: Electrostatic adsorption and ligand exchange or complexation with the hydroxyl groups on the surface of $\mathrm{Al} / \mathrm{Fe}(\mathrm{OH})_{3}(\mathrm{~s})$ (Lefebvre and Legube, 1993).

As far as phenolic compounds is concerned, Achak et al. (2008) reported on the one hand, that the coagulation-based removal process is more efficient when more positively charged $\mathrm{Al}$ species are generated, because the phenolic compounds are negatively-charged. On the other hand, the authors attributed the increase of abatement of polyphenols from $23 \%$ to $41 \%$ at $\mathrm{pH}$ range 6.31-7.08 (optimum $\mathrm{pH}$ ) to the change of coagulation mechanism. It passed from charge neutralizationprecipitation mechanism to adsorption mechanism. These results were in agreement with Yazdanbakhsh et al. (2015). In the same line, regarding the removal mechanisms of Al-based coagulants, Gregory and Duan (2001) reported that the positively-charged hydroxide precipitates act as destabilizing agents of organic compounds. The destabilization phenomenon occurs through the adsorptive deposition of the hydroxides on the surface of the negatively-charged particles, resulting in the charge neutralization of those particles. Besides, the positively charged metal-based precipitates could neutralize dissolved organic compounds, which lowers their solubility and promotes their precipitation (Pourrezaei et al., 2011). Rezeg and Achour (2005) studied the removal of gallic acid from water using sulphate aluminum at $\mathrm{pH}$ range (6-7). They concluded that the significant reduction of gallic acid can be explained by two mechanisms: Electrostatic charge neutralization by attraction of the partially dissociated organic compounds and mixture of the positively charged metal coagulant $\left(\mathrm{Al}(\mathrm{OH})_{2}{ }^{+}, \mathrm{Al}(\mathrm{OH})^{2+}\right)$ and amorphous $\mathrm{Al}(\mathrm{OH})_{3}$ and complexation with the hydroxyl groups on the surface of $\mathrm{Al}(\mathrm{OH})_{3}(\mathrm{~s})$.

In another study, Gursoy-Haksevenler and ArslanAlaton (2014) studied the removal of phenolic compounds from OMW using $2.5 \mathrm{~g} / \mathrm{L}$ of $\mathrm{FeCl}_{3}$ at optimum $\mathrm{pH}(\mathrm{pH}=7)$. Contrary to previous results, authors showed that the removal of phenolic compounds was insignificant (26\%). This behavior may be explained by the competitive complexation of the $\mathrm{OH}^{-}$as ligand with metal (iron or aluminum). Therefore, the hydrolysis reaction to $\mathrm{Al}(\mathrm{OH})_{3}$ or $\mathrm{Fe}(\mathrm{OH})_{3}$ forms could be promoted at the expense of complexation reaction of organic matter. In the same way, Julien et al. (1994) reported that the reaction between $\mathrm{OH}^{-}$and ferric pieces interferes with the formation of ferric-organism complexes and thus organic compounds removal efficiencies get lower.

Other research studies reported that the elimination of phenolic compounds by coagulation using inorganic coagulants depend on the number and the position of acid functions $(\mathrm{COOH}$ and/or $\mathrm{OH})$ on the aromatic cycle. According to Lefebvre and Legube (1993), the type of acid group seems to play a significant role on the removal percentage. The results obtained with 17 aromatic compounds (acids and/or phenolic compounds) coagulated at $\mathrm{pH} 5.5$ and at different doses $(15,30$ or 40 $\mathrm{mg} / \mathrm{L}$ ) using iron-based coagulant allowed to define four classes of aromatic compounds regarding their behavior during iron coagulation. Aromatics bringing with only one acidic group ( $\mathrm{COOH}$ or $\mathrm{OH})$ or more (two or three) non-adjacent were not removed, such as benzoic acid, phydroxybenzoic acid, phenol, protocatechuic acid, vanillic acid, veratric acid, tyrosol and pHydroxyphenylacetic acid (Table 2). However, aromatics bringing at least two adjacent acidic groups (ortho position) were more removed such as hydroxytyrosol, 3,4-dihydroxyphenylglycol, acid gallic and salicylic acid (Table 2). This result is in accordance with the works of Rezeg and Achour (2005) who found that the application of aluminum sulphate allowed an important removal of gallic acid $(72.58 \%)$ and pyrogallol $(53.58 \%)$ compared with phloroglucinol (10\%) (functions acid non-adjacent). Hecini and Achour (2014) also indicated that the efficiency of the coagulation using aluminum sulphate on the removal of organic compounds with phenolic functions (pyrogallo and phloroglucinol) depends on the number and position of phenolic groups on the molecules. The removal of some 
phenolic compounds (benzoic acid, phenol, naphtol, salicylique acid, etc.) by coagulation and adsorption on performed floc at $\mathrm{pH} 5.4$ using iron and at $\mathrm{pH} 6.8$ using aluminum showed a perfect performance for compounds with at least two acidic functions (Julien et al., 1994).

\section{Effect of Mineral Salts}

An important aspect to be taken into account when studying the removal efficiencies of phenolic compounds from olive mill effluent is the influence and effect of mineral salts. As shown in Table 2, OMW contains very considerable amount of mineral anions $\left(\mathrm{PO}_{4}{ }^{3-}, \mathrm{SO}_{4}{ }^{3-}, \mathrm{Cl}^{-}\right)$. These anions can affect the elimination efficiency of phenolic compounds from OMW. According to Clément et al. (1983), the removal of organic matter and widening of the optimum zone of the coagulation $\mathrm{pH}$ was mainly attributed to the affinity of the mineral anion towards the aluminum sulphate. Many studies (Afoufou et al., 2007; Hecini and Achour, 2014) showed that the removal efficiency of organic compounds with phenolic functional groups (pyrogallol and phloroglucinol) from mineralized waters using aluminum sulphate depends mainly the presence of sulphate, phosphate and chloride, who are considered such concurrent ligands for hydroxyl ions. On the other hand, the inhibitory effect of mineral anions could be explained by the adsorption of these anions on the hydroxides by lowering the surface charge or even, to the limit, making it change its sign (Hecini and Achour, 2014), as shown below:

$$
\operatorname{Metalx}(\mathrm{OH}) \mathrm{y})^{+\mathrm{n}}+\mathrm{SO}^{2-} \rightarrow\left(\operatorname{Metal}_{\mathrm{x}}(\mathrm{OH})_{\mathrm{y}-1} \mathrm{SO}_{4}^{(\mathrm{n}-1)+}\right)+\mathrm{OH}^{-}
$$

In another research studies, the mineral cations, such as $\mathrm{Ca}^{2+}, \mathrm{Mg}^{2+}$ and $\mathrm{Na}^{2+}$ appear to improve the removal efficiencies of phenolic compounds and optimize the $\mathrm{pH}$ range for coagulation. Afoufou et al. (2007) addressed that the removal of organic compounds with phenolic functional groups from mineralized water seemed very significant compared with distilled water. This result was attributed to bridging effect of cationic metal and negatively charged colloids. This approach is in correlation with the studies done by Bernhardt et al. (1986; Wais-Mossa and Mazet, 1991).

In order to explain the removal efficiencies of organic compounds with phenolic functional in the presence of cationic metals three mechanisms were carried out by to Afoufou et al. (2007):

- Adsorption of cations (i.e., $\mathrm{Ca}^{2+}$ ) on hydroxide flocs resulting in the creation of new adsorption sites:

$$
(\mathrm{Mex}(\mathrm{OH}) \mathrm{y})^{+\mathrm{n}}+\mathrm{Ca}^{2+} \rightarrow\left(\mathrm{Me}_{\mathrm{x}}(\mathrm{OH})_{\mathrm{y}-1} \mathrm{OCa}\right)+\mathrm{H}^{+}
$$

- Formation of insoluble complex $\left(\mathrm{Ca}^{2+}\right.$ - organic matter $)$
- The bridging effect of $\mathrm{Ca}^{+2}$ between the anionic forms of organic compounds and the negatively charged species of the coagulant at higher $\mathrm{pH}$ value

\section{Acid Cracking Coagulant}

The reduction of phenolic compounds from OMW by coagulation process using acid cracking $\left(\mathrm{H}_{2} \mathrm{SO}_{4}\right.$ or $\left.\mathrm{HCl}\right)$ has been investigated by numerous studies. Azbar et al. (2008) tested the treatment of OMW by coagulation with acid cracking at $\mathrm{pH}$ less than 2 . The results showed no significant removal of COD (15\%) and total phenol (4\%). Kestioglu et al. (2005) found the same result, acid cracking resulted only in $38 \%$ COD and $23 \%$ total phenol removal at $\mathrm{pH} 2.0$. In another study, the elimination of COD and phenolic compounds at acidic $\mathrm{pH}(\mathrm{pH} 2)$ did not exceed $46 \%$ and $37 \%$ respectively (Mert et al., 2010; Madani et al., 2015). In another comparative study, the effect of acid cracking was investigated at $\mathrm{pH} 2.0$ and allowed a low removal of COD (46\%) and total phenol (37\%) (Gursoy-Haksevenler and Arslan-Alaton, 2014; 2016). Recently, Gocer et al. (2017) also observed the same finding, a low removal of COD (46\%) and total phenol (38\%) with acid cracking $\mathrm{HCl}$ was detected.

From the above studies, it was find that removal of phenolic compounds and COD from OMW by coagulation with acid cracking was not efficient. For this reason, several studies showed that the usage of dual coagulants (acid cracking and inorganic metal coagulants) has benefits over the sole use of acid cracking and inorganic coagulants. These benefits are mostly related to the increase of effectiveness removal of phenolic compounds and organic matter and reduction of the inorganic coagulant dosage while producing larger, denser and stronger flocs (Lee et al., 2014).

Mert et al. (2010) studied the treatment of OMW using various combinations (acid cracking $+\mathrm{FeCl}_{3}$, acid cracking $+\mathrm{FeSO}_{4}$ and acid cracking $\left.+\mathrm{Al}_{2}\left(\mathrm{SO}_{4}\right)_{3}\right)$ with varying dosage under varying $\mathrm{pH}$ conditions. They concluded that $\mathrm{FeCl}_{3}$ dosage of $4 \mathrm{~g} / \mathrm{L}$ at $\mathrm{pH} 9$ resulted in best COD and phenol removal for OMW. Removal efficiencies increased from 46 to $67 \%$ for COD and from 37 to $72 \%$ for phenol when the OMW was first subjected to acid cracking. $\mathrm{FeSO}_{4}$ at $\mathrm{pH} 10$ and $4 \mathrm{~g} / \mathrm{L}$ dosage, the removal increase from 37 to $69 \%$ for phenol and from 46 to $66 \%$ for COD. While COD removal at a $\mathrm{Al}_{2}\left(\mathrm{SO}_{4}\right)_{3}$ dosage of $5 \mathrm{~g} / \mathrm{L}$ increase from 37 to $63 \%$ for phenol and from 46 to $64 \%$ for COD at $\mathrm{pH}$ 8. Application of acid cracking at $\mathrm{pH} 2$ alone and combined with $\mathrm{Al}_{2}\left(\mathrm{SO}_{4}\right)_{3}(6$ $\mathrm{g} / \mathrm{L})$ and $\mathrm{FeCl}_{3}(3 \mathrm{~g} / \mathrm{L})$ at optimum $\mathrm{pH} 8$ was suggested by Kestioglu et al. (2005). The results showed a very important reduction of COD and phenolic compounds for combined treatments. $\mathrm{FeCl}_{3}$ resulted in a $95 \%$ of COD and $90 \%$ of total phenol. On the other hand, $94 \%$ 
of $\mathrm{COD}$ and $91 \%$ of total phenol were observed in experiments using $\mathrm{Al}_{2}\left(\mathrm{SO}_{4}\right)_{3}$. $\mathrm{FeSO}_{4}, \mathrm{Al}_{2}\left(\mathrm{SO}_{4}\right)_{3}$ and $\mathrm{FeCl}_{3}$ were tested by Azbar et al. (2008), under predetermined optimum $\mathrm{pH}$ conditions after acid cracking with varying dosages (from 0.5 to $6 \mathrm{~g} / \mathrm{L}$ ) to compare the results and to choose the best for further biological treatment. The results reported that $\mathrm{FeSO}_{4}$ was the best chemical agent in terms of removing total phenol (53\%).

From the above considerations, it can be concluded that acid cracking alone is an inefficient way of removing COD and total phenol from OMW. However, the usage of dual coagulants (acid cracking + inorganic metal coagulants) removal more effectively organic matter. On the other hand, it was reported that during the coagulation process with acid cracking + iron-based coagulants is more effective in removing COD and phenolic compounds in comparison with acid cracking + aluminum based coagulants. Similarly, the results from other studies showed that iron-based coagulants are more effective in removing organic matter, due to the higher charge density of iron coagulants, compared to the aluminum-based counterparts (Hahn et al., 2002). According to Fitzpatrick et al. (2004; Xiao et al., 2010), the main reason for such difference is the formation of more and larger flocs during coagulation process involving iron coagulants, than those formed during aluminum-based coagulation.

\section{Inorganic Polymeric Coagulants}

As previously reviewed, the mineral coagulants based on aluminum and iron are one of the most widely used coagulants in conventional wastewater treatments. These coagulants reported a significant removal of COD and phenolic compounds from OMW at optimum $\mathrm{pH}$, in addition of their low cost, ease of use and availability. However, the application of these mineral substances is quite limited nowadays and has been reduced due to numerous disadvantages. As reported by many studies, its usage would cause two important environmental consequences (i) an increase in metal concentration in the treated water (which may have human health implications); (ii) production of large (toxic) sludge that is difficult to dehydrate (Ward et al., 2006; Alaoui Slimani et al., 2016; Zahrima et al., 2017). In order to minimize the drawbacks of inorganic coagulants, many factors have been taken into consideration to find the alternative and reduce the dosage of the harmful inorganic coagulants. Therefore, new types of reagents based on pre-hydrolysed forms of aluminium and iron have been developed (Ginos et al., 2006; Bratby, 2007). In this regard, the most studied and applied prehydrolyzed metal-ion coagulants are Poly-Aluminum Chloride (PAC) (Ginos et al., 2006; Wang et al., 2017; $\mathrm{Hu}$ et al., 2015), Poly-Ferric Chloride (PFC) (Cao et al., 2011), Poly-Ferric Sulfate (PFS) (Zouboulis et al.,
2008), as well as various composite inorganic coagulants such as Polymeric Aluminum Ferric Sulfate (PAFS) (Zhu et al., 2005), Polymeric Ferric Zinc Sulfate (PFZS) (Wei et al., 2016) and Polymeric Phosphate Aluminum Chloride (PPAC) (Zheng et al., 2011). In comparison with inorganic coagulants, some of the advantages of these polymers are: Lower coagulant dose requirements, increase in the rate of separating the solid and water phases arising from larger agglomerate sizes, efficiency at low temperatures (hydrolysing metal coagulants perform less well at low temperatures), a smaller volume of sludge, a smaller increase in the ionic load of the treated water, a less $\mathrm{pH}$-dependent process and a reduced level of aluminium in the treated water. Polymer-based products also improve settleability and increase the floc toughness (Renault et al., 2009). According to Cheng and Chi (2002) and Wei et al. (2016), the main organic matter removal mechanisms using inorganic polymeric coagulants were generally attributed to adsorption, entrapment, complexation, charge neutralization and to a lesser extent.

In previous studies, Jiang and Graham (1996; Jiang et al., 2016) reported that these inorganic polymeric coagulants showed better removal capacities toward organic matter from wastewaters at neutral $\mathrm{pH}$, in comparison with coagulants such as aluminum sulfate or ferric sulfate (Nandy et al., 2003). These results are in accordance with the studies of Ginos et al. (2006; BaiChuan et al., 2010). Ginos et al. (2006) revealed that the application of PAC $(1 \mathrm{~g} / \mathrm{L})$ at $\mathrm{pH} 4.7$ did not show any significant reduction of COD and phenolic compounds $(<10 \%)$. According to Nandy et al. (2003), this behavior may be due to the low solution $\mathrm{pH}$ since PAC is particularly effective for $\mathrm{pH}$ values above neutral. In the same line, BaiChuan et al. (2010) found that when the coagulation condition is acidic $(\mathrm{pH} 4)$, the coagulants (poly-ferric silicate sulphate, poly-ferric sulphate) tested did not perform well in organic compounds removal. This behavior may be explained by the fact that the carboxyl groups of organic compounds are difficult to be hydrolyzed due to the high concentration of $\mathrm{H}^{+}$. Furthermore, $\mathrm{H}^{+}$could react with organic molecules, which competed with the complex reaction between ferric pieces and organic compounds (Tipping et al., 1990).

\section{Potential of Lime based Coagulant}

The two forms of lime mostly used in wastewater treatment as coagulant are quicklime $(\mathrm{CaO})$ and hydrated lime $\left(\mathrm{Ca}(\mathrm{OH})_{2}\right)$, although its action and behavior are different from that of mineral coagulants and inorganic polymeric coagulants. When lime is added to the water, the $\mathrm{pH}$ increases, resulting in the formation of carbonate calcium from the natural alkalinity in the water:

$$
\mathrm{Ca}(\mathrm{OH})_{2}+\mathrm{H}_{2} \mathrm{CO}_{3} \leftrightarrow \mathrm{CaCO}_{3}+2 \mathrm{H}_{2} \mathrm{O}
$$


The increase in carbonic acid concentration and calcium added of the lime results in the precipitation of calcium carbonate $\left(\mathrm{CaCO}_{3}\right)$. The calcium carbonate crystals enmesh colloidal particles in the same way as aluminum or iron flocs. When lime is used as a coagulant, the $\mathrm{pH}$ has to be lowered in order to stabilize the water chemically. Carbon dioxide is normally used for this purpose, wherein the following reaction is involved:

$$
\mathrm{Ca}(\mathrm{OH})_{2}+2 \mathrm{CO}_{2} \leftrightarrow \mathrm{Ca}^{2+}+2 \mathrm{HCO}_{3}^{-}
$$

Moreover, apart from its positive economic impact in terms of chemical cost and energy requirement, lime was effectively considered by several studies to remove the suspended, colloidal material and mainly phenolic compounds.

Ginos et al. (2006) investigated the effectiveness of using lime as coagulant agent in removing of phenolic compounds from OMW. The results demonstrated that phenolic compounds content decrease considerably $(67 \%)$ at solution $\mathrm{pH} 11.4$ and at $60 \mathrm{~g} / \mathrm{L}$ of $\mathrm{Ca}(\mathrm{OH})_{2}$. The comparison of effectiveness phenolic compounds removal using $\mathrm{Ca}(\mathrm{OH})_{2}$ and mineral coagulants $\left(\mathrm{FeCl}_{3}, \mathrm{MgSO}_{4}\right.$ and $\mathrm{FeSO}_{4}$ ) showed in addition to a higher removal efficiency of lime, these materials may be advantageous over lime because (i) the concentration needed is considerably lower than that with lime to achieve comparable removals, (ii) the change of solution $\mathrm{pH}$ following lime addition is far greater than that with other materials and (ii) lime generates greater volume of sludge.

In another work, Achak et al. (2008) studied the removal of organic matter from OMW using a range of lime between 5 and $30 \mathrm{~g} / \mathrm{L}$. At optimum conditions, i.e., $20 \mathrm{~g} / \mathrm{L}$ of lime and solution $\mathrm{pH} \mathrm{12,} \mathrm{the} \mathrm{phenolic}$ compounds and COD removal were about $75 \%$ and
$43 \%$ respectively. The authors concluded that the entrapment of suspended and colloidal particles by lime is carried out through the sweep coagulation mechanism. On the other hand, the calcium carbonate formed at basic $\mathrm{pH}$ acts as a weighting agent by increasing the density of the settle able particles, thereby enhancing their settlement.

In other studies, the impact of lime pre-treatment on phenols removal for seventeen different olive mill effluent was evaluated. The precipitation with lime (15 $\mathrm{g} / \mathrm{L}$ ) allows the elimination of $65 \%$ of polyphenols and only $28 \%$ of volatile phenols (Aktas et al., 2001). The phenolic compounds could be removed totally or partially and some of them were not affected as shown in Fig. 2. According to Aktas et al. (2001), this behavior was accorded to the structures and number of acid functions $(\mathrm{COOH}$ and/or $\mathrm{OH})$ on the aromatic cycle, it was observed that the substances with two phenolic groups in the molecule (catechin) which are highly phytotoxic were totally removed, the substances which contain both phenolic and carboxyl groups (vanillic acid, syringic acid) were adsorbed partially and the substances which have only one phenolic or carboxyl group (tyrosol, veratric acid) were not affected by lime. This finding was in accordance with results obtained by Jaouani et al. (2005; Boukhoubza et al., 2009).

Once again, the treatment of the effluent with increasing concentrations of $\mathrm{CaO}$ showed that the minimal amount of lime was sufficient for effective removal of the phenols (71\%) in the range $\mathrm{pH}$ of 12-12.4 (Jaouani et al., 2005). The comparison of the results obtained with lime and $\mathrm{FeCl}_{3}$, allowed authors to conclude that lime was more effective to eliminate phenols from the OMW (71\% against $44 \%$ for $\mathrm{FeCl} 3$ ), particularly for high molecular weight fraction.

Table 4: Selected research studies on the removal of COD and phenolic compounds from OMW by coagulation process using acid cracking alone and combined with metal coagulants

\begin{tabular}{|c|c|c|c|c|c|c|c|}
\hline OMW origin & Phenols (g/L) & $\operatorname{DCO}(\mathrm{g} / \mathrm{L})$ & $\begin{array}{l}\text { Acid cracking+coagulant } \\
\text { concentration }(\mathrm{g} / \mathrm{L})\end{array}$ & Phenols \% & $\mathrm{DCO} \%$ & $\mathrm{pH}$ & Ref. \\
\hline \multicolumn{8}{|l|}{ Extraction process } \\
\hline Turkey (3-phase) & 3.7 & 128.1 & Acid cracking $\mathrm{H}_{2} \mathrm{SO}_{4}$ & 31 & 53 & 1.3 & Kiliç et al. (2009) \\
\hline \multirow[t]{2}{*}{ Turkey (3-phase) } & 0.2 & 38.07 & Acid cracking $\mathrm{HCl}$ & 46 & 38 & 1.5 & Gocer et al. (2017) \\
\hline & & & Acid cracking $\mathrm{H}_{2} \mathrm{SO}_{4}$ & 66 & 17 & 2 & \\
\hline \multirow[t]{4}{*}{ Turkey (3-phase) } & 5.58 & 115 & Acid cracking $\mathrm{H}_{2} \mathrm{SO}_{4}$ & 37 & 46 & 2 & Mert et al. (2010) \\
\hline & & & Acid cracking $+\mathrm{FeCl}_{3}(4.0)$ & 72 & 67 & 9 & \\
\hline & & & Acid cracking+FeSO 4 (4.0) & 69 & 66 & 10 & \\
\hline & & & Acid cracking $+\mathrm{Al}_{2}\left(\mathrm{SO}_{4}\right)_{3}(5.0)$ & 63 & 64 & 8 & \\
\hline \multirow[t]{4}{*}{ Turkey (3-phase) } & 3.8 & 150 & Acid cracking $\mathrm{H}_{2} \mathrm{SO}_{4}$ & 39 & 58 & 2 & Gursoy-Haksevenler and \\
\hline & & & Acid cracking+ $\mathrm{FeCl}_{3}(2.5)$ & 45 & 61 & 7 & Arslan-Alaton (2014) \\
\hline & & & Acid cracking $+\mathrm{FeCl}_{3}(2.5)$ & 47 & 62 & 3 & \\
\hline & & & Acid cracking $+\mathrm{Ca}(\mathrm{OH})_{2}(6.7)$ & 47 & 63 & 11 & \\
\hline \multirow[t]{3}{*}{ Turkey (3-phase) } & 9.68 & 185.6 & Acid cracking $\mathrm{H}_{2} \mathrm{SO}_{4}$ & 23 & 38 & 2 & Kestioglu et al. (2005) \\
\hline & & & Acid cracking $+\mathrm{Al}_{2}\left(\mathrm{SO}_{4}\right)_{3}(6.0)$ & 91 & 94 & 8 & \\
\hline & & & Acid cracking $+\mathrm{FeCl}_{3}(3.0)$ & 90 & 95 & 8 & \\
\hline \multirow[t]{4}{*}{ Turkey (3-phase) } & 4.03 & 97.6 & Acid cracking $\mathrm{H}_{2} \mathrm{SO}_{4}$ & 4 & 15 & 2.2 & Azbar et al. (2008) \\
\hline & & & Acid cracking $+\mathrm{FeCl}_{3}(6.0)$ & 19 & 27 & 7 & \\
\hline & & & Acid cracking $+\mathrm{Al}_{2}\left(\mathrm{SO}_{4}\right)_{3}(6.0)$ & 27 & 47 & 7 & \\
\hline & & & Acid cracking $+\mathrm{Fe}_{2} \mathrm{SO}_{4}(6.0)$ & 53 & 30 & 7 & \\
\hline
\end{tabular}




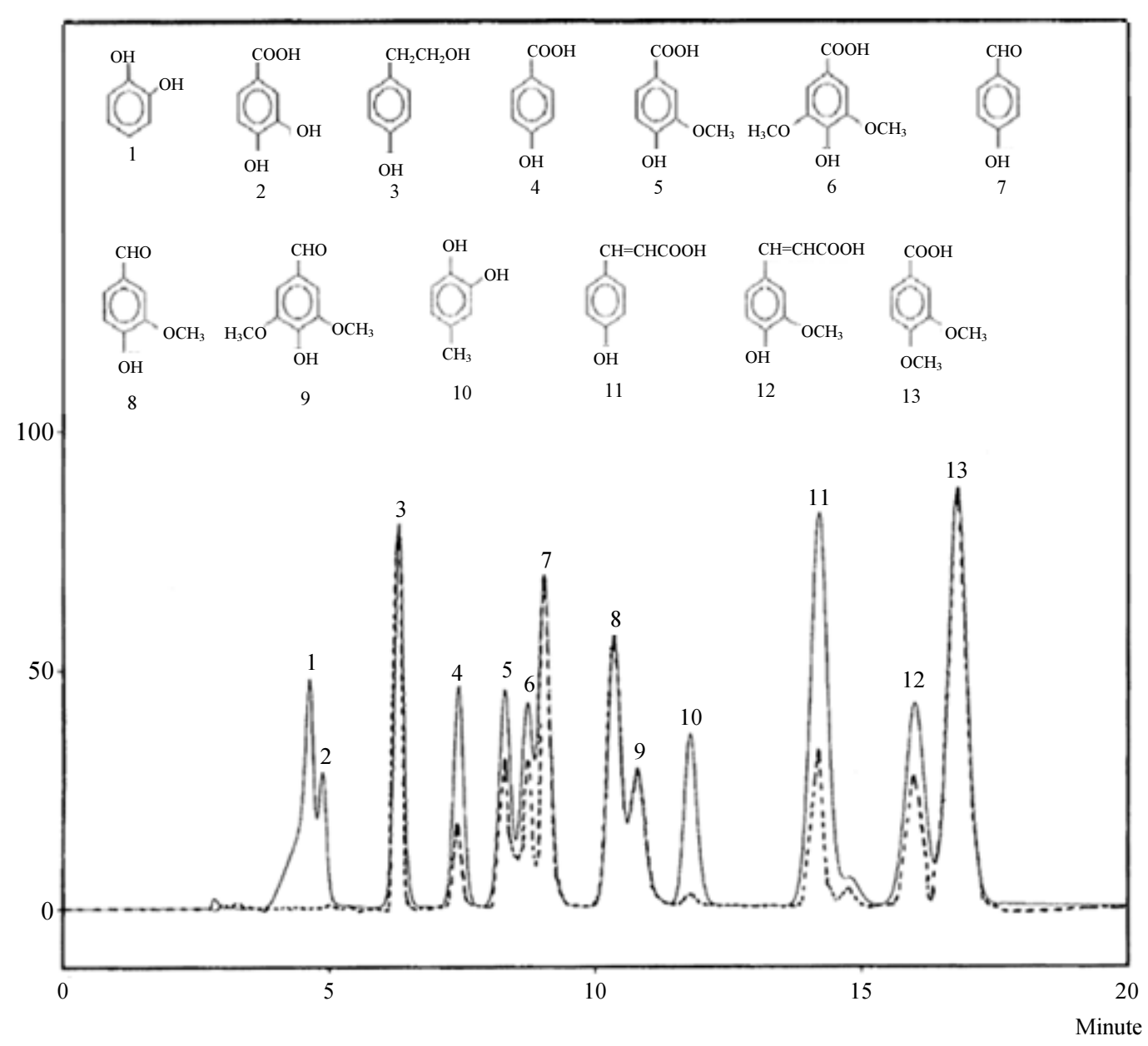

Fig. 2: The HPLC chromatograms of artificial phenolic mixture before (-) and after (-) lime treatment. (1) catechin, (2) protocatechuic acid, (3) tyrosol, (4) p-hydroxybenzoic, (5) vanillic acid, (6) syringic acid, (7) p-hydroxybenzaldehyde, (8) vanillin, (9) sringaldehyde, (10) 4-methylcatechol, (11) p-coumaric acid, (12) ferulic acid and (13) veratric acid (Aktas et al., 2001)

In the same way, Kissi et al. (2001) showed that the utilization of lime could be considered as a very effective, economical and high performance depurative mean of OMW pre-treatment, mainly if it takes into account its important role in the odor's elimination and its availability at low prices in countries like Morocco.

Alaoui Slimani et al. (2016) reported that the addition of $\mathrm{CaO}(7.5 \mathrm{~g} / \mathrm{L})$ allowed the adjustment of the acidic $\mathrm{pH} 4.6$ to a basic $\mathrm{pH} 10$. The neutralization by lime leads the transformation of phenols to phonates with the formation of $\mathrm{C}_{6} \mathrm{H}_{5} \mathrm{O}^{-}$ions (Macheix et al., 1990). The authors indicated a significant elimination of polyphenols $(68 \%)$ and COD (40\%). Similar results were reported by Aktas et al. (2001).

In addition, to the simplicity and effectiveness of lime application in reduction of phenolic compounds in the OMW, a large amount of the fatty components, which prevent the evaporation of water by forming an impermeable film on the surface of the wastewater in the ponds, can be removed. After lime application, the $\mathrm{pH}$ was brought to 12 , some toxic or hard-to-degrade constituents of the OMW were eliminated and the remaining pollutants could be treated biologically after neutralization. It is also known that application of lime shortens the required retention time in settling lagoons and sludge resulting from storage could be either composed or mixed with olive mill solids wastes before disposal or other operations and uses. In the same line, many authors indicated that the recycle of sludge could be a viable alternative. In this regard, the innovative use of sludge for example as a fuel (Van der Bruggen et al., 2003), a soil conditioner (Nigam et al., 2000; Pearson et al., 2004), a combustion matter (Alaoui Slimani et al., 2016) or a building material (Balasubramanian et al., 2006) has been studied by several researchers.

In order to reduce the large amount of sludge produced and enhance the removal efficiency of organic matter from OMW by lime, the combination of lime and inorganic coagulants have been developed by many studies. The effects of coagulation process using acid 
cracking combined with $\mathrm{Ca}(\mathrm{OH})_{2}$ were examined by Gursoy-Haksevenler and Arslan-Alaton (2014). For this purpose, $6.7 \mathrm{~g} / \mathrm{L} \mathrm{Ca}(\mathrm{OH})_{2}$ was added to OMW at $\mathrm{pH} 11.0$. $\mathrm{Ca}(\mathrm{OH})_{2}$ precipitation carried out without acid cracking resulted in $56 \% \mathrm{COD}, 30 \%$ phenols removals, whereas for combined treatment, removal efficiencies were 63\% COD and $47 \%$ phenols (Table 4). Alaoui Slimani et al. (2016) evaluated the evolution of removal of COD and phenolic compounds from OMW after treatment with $\mathrm{CaO}$ and $\mathrm{FeCl}_{3}$. According to their results, the addition of $\mathrm{FeCl}_{3}$ as an inorganic coagulant allowed an important removal of organic matter. The reduction of COD and polyphenols is respectively 58 and $75 \%$. $\mathrm{FeCl}_{3}$ allowed the passage of the dissolved form of pollutants to an insoluble particulate form that can be easily retained by simple decantation and gives settleable floc (Yaakoubi et al., 2010). In another study, Achak et al. (2008) revealed that the successive addition of $\mathrm{Ca}(\mathrm{OH})_{2}$ to $1.5 \mathrm{~g} / \mathrm{L}$ of $\mathrm{Al}_{2} \mathrm{SO}_{4}$ raised the $\mathrm{pH}$ at $10 \mathrm{~g} / \mathrm{L}$ of $\mathrm{Ca}(\mathrm{OH})_{2}$ and induced a removal of COD $(38 \%)$ and polyphenols $(54 \%)$ at a dose of $20 \mathrm{~g} / \mathrm{L}$ of $\mathrm{Ca}(\mathrm{OH})_{2}$. The successive addition of aluminium sulphate to $15 \mathrm{~g} / \mathrm{L}$ of $\mathrm{Ca}(\mathrm{OH})_{2}$ involved only a slight variation of the $\mathrm{pH}$ and allowed the elimination of COD (36\%) and polyphenols (35\%) at a dose of $3 \mathrm{~g} / \mathrm{L}$ of $\mathrm{Al}_{2} \mathrm{SO}_{4}$. Contrary to previous studies, the comparison between the two coagulant combinations indicated that $\mathrm{Al}_{2} \mathrm{SO}_{4}$ combined with $\mathrm{Ca}(\mathrm{OH})_{2}$ did not show any significant enhance in removing of COD and phenolic compounds, the best coagulation was obtained by application of $20 \mathrm{~g} / \mathrm{L}$ of lime used alone.

\section{Removal of Phenolic Compounds from OMW by Direct Flocculation Process}

As previously reported, the coagulation process using inorganic coagulants and acid cracking is not always perfect in removing COD and phenolic compounds from OMW, due generally to the formation of small flocs when coagulation takes place or generation of fragile flocs which break up when subjected to physical forces. It is not only necessary to overcome these problems but also to improve the process in order to obtain good quality effluent and rapid sedimentation of the flocs formed. To do so, direct flocculation process was proposed and investigated by several studies (Sarika et al., 2005; Ginos et al., 2006; Iakovides et al., 2014; Hodaifa et al., 2015; Lourenço et al., 2017). Recently, many synthetic organic polymers have been used as the main flocculants such us polyacrylamide, polyacrylic acid, poly (diallyl dimethyl ammonium chloride) (poly DADMAC), cyanoguanidine, polyamine etc. and they are classified into four forms: Positively charged (cationic), negatively charged (anionic), amphotric (contains both cationic and anionic groups) and neutral (non-ionic). Ionic polymers or "polyelectrolytes" of various structures are usually used as coagulant aids to enhance the formation of larger floc in order to improve the rate of sedimentation (Bratby, 2007; Iakovides et al., 2014). The effect on the efficient of flocculation process depends mainly on polymer weight, structure (linear versus branched), amount of charge, charge type and composition. Table 5 shows the main characteristic of several polyelectrolytes used. The nature of the charges is the main parameter that will have significant effect followed by molecular mass and charge density (Lee et al., 2014). In addition, according to Bohuslav Dobias (2005), the parameters that are measured to justify flocculation efficiency include settling rate of flocs, sludge volume produce, amount of pollutants removal and turbidity or supernatant clarity.

In practice, many studies are promoting the application of synthetic organic polymers, as primary coagulants in water and wastewater treatment system, more than metal-based coagulants (Bolto et al., 1998; Bolto and Gregory, 2007; Matilainen et al., 2011; Iakovides et al., 2014; Hodaifa et al., 2015), because they offer significant advantages in flocculation process. Polymeric flocculants are easy to handle and immediately soluble in aqueous systems, do not affect the $\mathrm{pH}$ of the medium and it is possible to synthesize them with various functions (positive, negative or neutral charge) with various molecular mass and charge density where it can be used to produce a good settling performance at relatively low cost (Ahmad et al., 2008). The concentration of polymers used for direct flocculation is workable at any $\mathrm{pH}$ condition: Acidic, neutral and basic medium (for example polyamines are effective over a wide range of $\mathrm{pH}$ ). This behavior is in contrast with the coagulation process where the effective treatment was obtained by precipitation of metal hydroxides at adjusting $\mathrm{pH}$. In addition, the concentrations needed of flocculants are only a few millimeters per liter and generate less volume of nonhazardous sludge because the flocs formed are dense, large, compact and closely packed. Concerning the treatment cost, Lee et al. (2014) noted that direct flocculation cost is at least 3.6 times lower than coagulation-flocculation treatment due to larger volumes of phyto-toxic sludge produced from coagulation-flocculation process.

For the case of phenolic compounds and COD removal from OMW, various polyelectrolytes were mostly applied (Table 6). Ginos et al. (2006) studied six polymers of polyacrylamide, which have all a high molecular mass, for treatment of OMW. Four cationic polymers allowed a considerably removal of phenolic compounds (54-58\%) and COD (10-30\%) at a common concentration of $287 \mathrm{mg} / \mathrm{L}$. However, two anionic polymers did not show any significant remove of these compounds. According to Lee et al. (2014), the main coagulation mechanism for organic matter and phenolic 
compounds (negatively charged) removal using cationic polymers is charge neutralization. In general, neutralization charge takes place when the flocculants and the adsorption site are of opposite charge. The flocculation results of the reduced surface charge of the particles and hence a decreased electrical repulsion force between colloidal particles (mainly phenolic compounds), which allows the formation of Van Der Waals force of attraction to encourage initial aggregation of colloidal and fine suspended materials to form micro flocs (Fig. 3).
In research of Hodaifa et al. (2015), five organic polymers (three cationic and two anionic) have been used to achieve the separation of phases (liquid treated-sludge) at different concentrations (1-1000 $\mathrm{mg} / \mathrm{L})$. The results showed a slight reduction of total phenols (11.3-25.1\%) and COD (5.6-20.4\%). In this study, authors concluded that the elimination of the total phenolic compounds by flocculants was instantaneous in the case of all cationic flocculants. However, the removal of total phenols was proportional to the dose of flocculants used. (a)
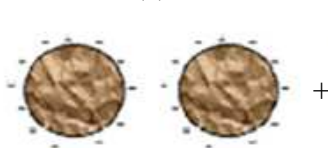

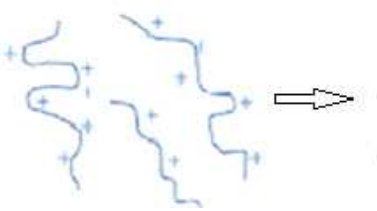

(b)

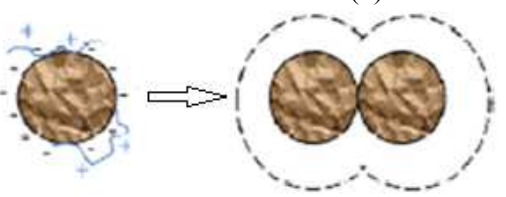

Fig. 3: Flocculation mechanism by charge neutralization (a) particles negatively charged and cationic polymers (b) adsorption of polymers onto the surface of particles (c) flocculation

Table 5: Characteristics of several polyelectrolytes

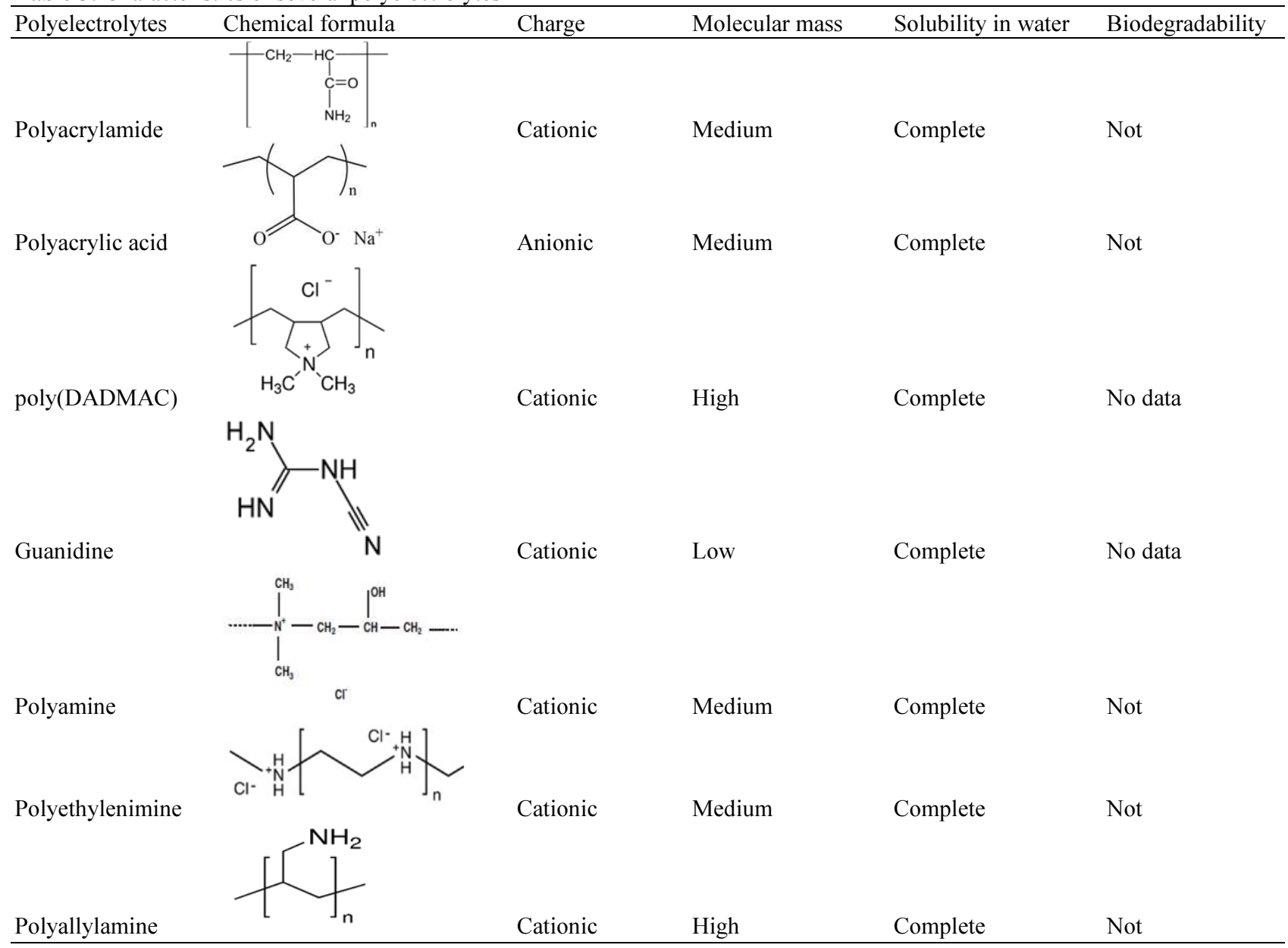


Table 6: Direct flocculation process with polyelectrolyte for the COD and phenolic compounds removal

\begin{tabular}{|c|c|c|c|c|c|c|c|c|}
\hline OMW origin & Phenols $(\mathrm{g} / \mathrm{L})$ & $\mathrm{DCO}(\mathrm{g} / \mathrm{L})$ & Flocculant & Charge & Dose $(\mathrm{g} / \mathrm{L})$ & Phenols \% & DCO \% & Ref. \\
\hline \multicolumn{9}{|l|}{ Extraction process } \\
\hline \multirow[t]{4}{*}{ Greece (3-phase) } & n.d & 89.2 & FLOCAN 23 & Anionic & 3 & n.d & 38 & Sarika et al. (2005) \\
\hline & & & FO-4700 & Cationic & 3 & n.d & 32 & \\
\hline & & & FO-4490 & Cationic & 3 & n.d & 28 & \\
\hline & & & FO- 43.50 & Cationic & 3 & n.d & 28 & \\
\hline \multirow[t]{4}{*}{ Greece (3-phase) } & n.d & 57.1 & FLOCAN 23 & Anionic & 3 & n.d & 20 & \\
\hline & & & FO-4700 & Cationic & 3 & n.d & 40 & \\
\hline & & & FO-4490 & Cationic & 3 & n.d & 22 & \\
\hline & & & FO- 43.50 & Cationic & 3 & n.d & 55 & \\
\hline \multirow[t]{4}{*}{ Greece (2-phase) } & n.d & 4.5 & FLOCAN 23 & Anionic & 0.033 & n.d & 33 & \\
\hline & & & FO-4700 & Cationic & 0.066 & n.d & 70 & \\
\hline & & & FO-4490 & Cationic & 0.033 & n.d & 62 & \\
\hline & & & FO- 43.50 & Cationic & 0.17 & n.d & 18 & \\
\hline \multirow[t]{4}{*}{ Greece (3-phase) } & 3.5 & 61 & FO-4700 & Cationic & 0.28 & 56 & 20 & Ginos et al. (2006) \\
\hline & & & FO-4490 & Cationic & 0.28 & 58 & 30 & \\
\hline & & & FO- 43.50 & Cationic & 0.28 & 56 & 30 & \\
\hline & & & FO- 4190 & Cationic & 0.28 & 54 & 10 & \\
\hline \multirow{2}{*}{ Greece (3-phase) } & 3.5 & 61 & AN 934 & Anionic & 0.28 & 30 & 20 & \\
\hline & & & FLOCAN 23 & Anionic & 0.28 & 50 & 28 & \\
\hline \multirow[t]{5}{*}{ Spain (2-phase) } & 0.17 & 24.3 & Floc CS49 & Cationic & 1 & 17 & 16 & Hodaifa et al. (2015) \\
\hline & & & Floc CS45 & Cationic & 1 & 24 & 17 & \\
\hline & & & Floc CS51 & Cationic & 0.3 & 12 & 5.6 & \\
\hline & & & QG2001 & Anionic & 0.1 & 17 & 20.4 & \\
\hline & & & Nalco 9913 & Anionic & 0.4 & 11 & 13 & \\
\hline \multirow[t]{2}{*}{ Greece (3-phase) } & 1.98 & 40.93 & PDADMAC & Cationic & 2 & 35 & 46 & Iakovides et al. (2014) \\
\hline & & & PEI & Cationic & 5 & 15 & 35 & \\
\hline \multirow[t]{2}{*}{ Greece (3-phase) } & 2.99 & 82.45 & PAA & Cationic & 1.5 & 40 & 36 & \\
\hline & & & PAH & Cationic & 3 & 21 & 32 & \\
\hline \multirow{4}{*}{ Portugal (3-phase) } & n.d & 11.8 & $60 \mathrm{MC}$ & Cationic & 0.05 & n.d & 46 & Lourenço et al. (2017) \\
\hline & & & $60 \mathrm{MP}$ & Cationic & 0.05 & n.d & 44 & \\
\hline & & & $60 \mathrm{M} 1 \mathrm{SC}$ & Cationic & 0.05 & n.d & 47 & \\
\hline & & & $60 \mathrm{M} 2 \mathrm{SC}$ & Cationic & 0.05 & n.d & 34 & \\
\hline
\end{tabular}

PDADMAC: Polydiallyl Dimethyl Ammonium Chloride; PEI: Polyethylenimine; PAH: Polyallylamine Hydrochloride; PAA: Polyallylamine

In another study, the application of various polyelectrolytes (PDADMAC, polyethylenimine (PEI), polyallylamine hydrochloride $(\mathrm{PAH})$ and polyallylamine (PAA)) in removing of organic load of olive oil industry wastewater gave encouraging results (Iakovides et al., 2014). The polyelectrolytes used were chosen according to their high molecular mass and their positive charge. The results showed that the utilization of PDADMAC $(2000 \mathrm{mg} / \mathrm{L})$, PAH $(3000 \mathrm{mg} / \mathrm{L})$, PEI $(5000 \mathrm{mg} / \mathrm{L})$ and PAA $(1500 \mathrm{mg} / \mathrm{L})$ allowed $46 \%, 32 \%, 35 \%$ and $36 \%$ COD and $35 \%, 21 \%, 15 \%$ and $40 \%$ phenolic compounds removal respectively. Iakovides et al. (2014) concluded that PDADMAC is suitable for phenolic compounds removal, whereas PAA is suitable for COD removal. The removal mechanism of phenolic compounds from OMW using PDADMAC and PAA may be due to polymer bridging. In general, polymer bridging with longer chains (high molecular weight) is more effective than a one with shorter chains (low molecular weight) according to Razali et al. (2011). Indeed, when the polyelectrolytes is in contact with a colloidal particle (mainly phenolic compounds), some of its functional groups are adsorbed on the surface of the particle while other surfaces of the polymer remains unoccupied (Fig. 4). This behavior allows polyelectrolytes to be extended into solution and produce loops and tails to promote bridging of flocs (Fig. 4).

Sarika et al. (2005) studied the treatment of three different olive oil processing effluents by means of direct flocculation using four cationic and two anionic polyelectrolytes. Although most of them were found capable of removing considerably the concentration of $\mathrm{COD}$, without altering solution $\mathrm{pH}$, One of the cationic polyelectrolyte appears to be the most promising flocculant concerning the treatment of olive mill effluent from three-phase by about 55\% COD reduction.

Recently, Lourenço et al. (2017) studied the development of new, hydrophobically modified, flocculants directed to oily effluents application. Four cationic polyelectrolytes $(60 \mathrm{Mc}, 60 \mathrm{MP}, 60 \mathrm{M} 1 \mathrm{SC}$ and 60 M2SC) were synthesized using two different healthfriendly formulations and applied as low dosage flocculation agents in the pre-treatment step for OMW. This study revealed that the hydrophobic modification improves noticeably the flocculation performance of cationic polyelectrolytes in the treatment of OMW. In the best conditions, it was possible to achieve 47\% COD removal with only $53 \mathrm{mg} / \mathrm{L}$ of flocculant. Contrary to previous studies, encouraging results were obtained after addition of only $13 \mathrm{mg} / \mathrm{L}$ of modified flocculants. 
(a)

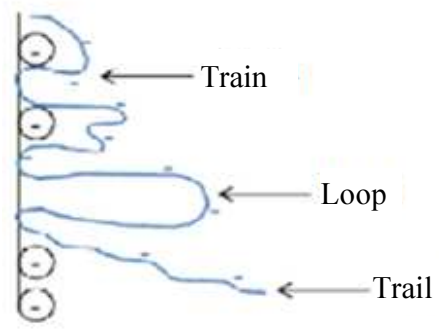

(b)

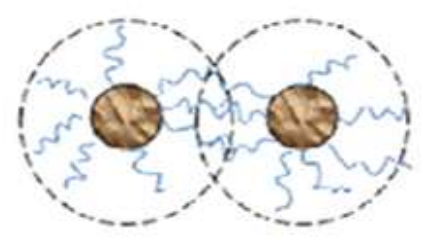

(c)

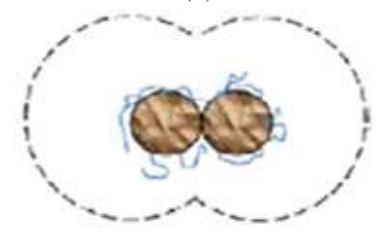

Fig. 4: Flocculation mechanism by bridge formation (a) adsorption of polymer onto the surface of particles (b) polymer bridging between particles (aggregation) (c) flocculation

\section{Removal of Phenolic Compounds from OMW by Coagulation-Flocculation Process}

Coagulation-flocculation is a chemical water treatment process where the cation inorganic salts are commonly used as coagulants and synthetic organic polymers are usually employed as flocculants (Michael et al., 2014; Lourenço et al., 2017; Sillanpaa et al., 2018). Coagulation tends to overcome the factors that promote particles stability and form agglomerates or flocs. Flocculation is the process of whereby destabilized particles, or particles formed as a consequence of destabilization, are induced to come together, make contact and thereby form large(r) agglomerates.

As previously reported, the coagulation process is not always perfect as it may result in small flocs when coagulation takes place or produce fragile flocs, which break up when subjected to physical forces. Also, in direct flocculation process, the majority of synthetic organic polymers used are resistant to biodegradation, which is usually extremely slow (Bolto and Gregory, 2007; Brostow et al., 2009) and their application is mostly limited to organic-based wastewater with high concentration of suspended and colloidal solids (Lee et al., 2014). For these reasons, there is an increasing demand to reduce dosage of the harmful inorganic coagulants and organic flocculants and to improve the process to removal organic load from OMW. In this respect, many studies tried to investigate the combination of coagulation and direct flocculation processes in removing COD and phenolic compounds from OMW. According to Radoiu et al. (2004), the use of flocculants not only can increase the density and the solidity of the flocs formed, it also can reduce the consumption of coagulants and increases the reliability of the work and the throughput capacity of the treatment plant.

As presented in Table 7, many studies have proved that the addition of a polymeric flocculants to an inorganic coagulants showed better removal where it was effective in the reduction of environmental concerned parameters (COD and phenolic compounds), reduce the amount of coagulant used and thus reduced the cost of the coagulation/flocculation process (Sarika et al., 2005;
Ginos et al., 2006; Pelendridou et al., 2014; Michael et al., 2014; Iakovides et al., 2014; Papaphilippou et al., 2013; Ioannou-Ttofa et al., 2017).

Iakovides et al. 2014 reported that the combination of calcium hydroxide $(20 \mathrm{~g} / \mathrm{L})$ as coagulant and PDADMAC $(1.25 \mathrm{~g} / \mathrm{L})$ as flocculant exhibited the best results, up to $76 \%$ and $56 \%$ in terms of phenolic compounds and COD reduction respectively. According to the authors, the explanation of this behavior might be the high $\mathrm{pH}$ value ( $\mathrm{pH} 13)$ of solution, which leads to their destruction.

The treatment of two different OMW units (W1, W2) by means of coagulation-flocculation using Polyaluminum Chloride (PAC)/FLOCAN 23-20 and Aluminum Sulphate (ASM)/Praestol 2240 was investigated by Pelendridou et al. (2014). The results demonstrated that the use of combination of PAC/FLOCAN 23-20 is advantageous over ASM coagulation with anionic polyelectrolyte Praestol 2240. The maximum removal of COD and phenolic compounds corresponded to a concentration of $4 \mathrm{~g} / \mathrm{L}$ of PAC and $0.01 \mathrm{~g} / \mathrm{L}$ of FLOCAN 23-20 was 36\% and $45 \%$ respectively. While the addition of ASM at various concentrations had practically no effect on COD and phenolic compounds removal. Pelendridou et al. (2014) reported that the one possible reason for the nonstable behavior of ASM is its chemical structure. Specifically, the presence of sulfate ions $\left(\mathrm{SO}_{4}{ }^{2-}\right)$ in the solution can lead to the partial sorption of the some sulfate ions in the Stern layer. On the other hand, the different coagulant concentration demand for W1 $(4 \mathrm{~g} / \mathrm{L})$ and W2 (2g/L) using PAC/ FLOCAN 23-20 combination lies primarily in the wastewater composition as $\mathrm{W} 1$ has a high organic content than W2 (Pelendridou et al., 2014).

Papaphilippou et al. (2013) investigated the combination of $\mathrm{FeSO}_{4}(6.67 \mathrm{~g} / \mathrm{L})$ as coagulant and FLOCAN $23(0.28 \mathrm{~g} / \mathrm{L})$ as flocculant. They stated that the COD and phenolic compounds removal was $72 \%$ and $40 \%$ respectively, as reported in a study by Ioannou-Ttofa et al. (2017; Michael et al., 2014). Decreasing coagulant dosage at $5 \mathrm{~g} / \mathrm{L}$ (while keeping the flocculant concentration unchanged) resulted in COD and phenolic compounds removal slightly dropped to $68 \%$ and $30 \%$ respectively. 
Ginos et al. (2006) who studied OMW treatment by coagulation-flocculation using $5 \mathrm{~g} / \mathrm{L}$ of $\mathrm{FeSO}_{4}$ and 0.287 $\mathrm{g} / \mathrm{L}$ of FLOCAN 23, reported a low COD (21.8\%) and phenolic compounds (33.2\%) reduction. Discrepancies between the two studies may be attributed to different operating conditions such as (i.e., longer stirring times were employed in Papaphilippou et al. (2013) study), as well as different OMW samples tested.

In another study, Ginos et al. (2006) studied the effect of coupling $5 \mathrm{~g} / \mathrm{L} \mathrm{FeSO}_{4}$ or $30 \mathrm{~g} / \mathrm{L} \mathrm{Ca}(\mathrm{OH})_{2}$ with four cationic flocculants (FO-4700, FO-4490, FO- 43.50, FO- 4190 referred to as $\mathrm{K} 1-\mathrm{K} 4$ respectively) and Two anionic flocculants (AN 934 and FLOCAN 23 referred to as $\mathrm{A} 1$ and $\mathrm{A} 2$ respectively). In all cases, a common flocculation concentration of $0.28 \mathrm{mg} / \mathrm{L}$ was employed. The majority of the tested flocculants led the moderate removal of COD (10-30\%) and significant removal of phenolic compounds (12.5-60\%). Ginos et al. (2006) also reported that the coagulation-flocculation with $\mathrm{Ca}(\mathrm{OH})_{2}$ always resulted in greater total phenols removal than treatment with $\mathrm{FeSO}_{4}$ with reduce the dosage of $\mathrm{Ca}(\mathrm{OH})_{2}$ used (Table 3 and 7).

Synthetic study of phenolic compounds removal from OMW by coagulation, direct flocculation and coagulation-flocculation processes.

The chemical composition of OMW is highly variable depending on various factors, such as the olive type, the geographical and climatic conditions, the tree age, the cultivation system, the degree of maturity of the fruit, the type of oil extraction process applied, the use of pesticides and fertilizers, etc. (Kallel et al., 2009; Yay et al., 2012). More specifically, OMW contain significant amounts of suspended, dissolved and colloidal matter were also relatively high as compared with most industrial effluents. Through the years, researchers have tested a variety of technologies for OMW treatment. Among of theme, coagulation/flocculation is one of the most widely used solid-liquid separation process for the removal of suspended and dissolved matter, colloid and organic matter present in OMW (Gursoy-Haksevenler and Arslan-Alaton, 2014).

Coagulation process is the conventional treatment method where the cationic inorganic metal salts are commonly used as coagulants. Generally, phenolic compounds are in form of colloidal suspensions and dissolved organic matters consisting of negatively charged particles. When particles are similarly charged, the resulting repulsive forces tend to stabilize the suspension and prevent particle agglomeration. In order to achieve destabilization of particles and enhance the removal percentage of phenolic compounds, several mechanisms were proposed such as charge neutralization, Adsorptionprecipitation, electrostatic patch coagulation and complexation with coagulant's metal ions into insoluble aggregates (Duan and Gregory, 2003; Crittenden et al., 2005; Henderson et al., 2006). The most commonly used coagulants in OMW treatment are the trivalent salts of iron and aluminum, ferrous sulfate and calcium hydroxide. According to the related literature, the efficiency of coagulation process to remove organic matter and phenolic compounds from OMW mainly depends on the coagulant's type and dosage, $\mathrm{pH}$, mixing conditions, organic load of solution and the presence of divalent cations and destabilizing anions such as bicarbonate, chloride, calcium and sulfate ions (Afoufou et al., 2007; Hecini and Achour, 2014). According to many studies, coagulation process is one of the most economical and environmentally friendly methods suitable for the treatment of OMW.

Table 7: Removal efficiencies of OMW treatment using coagulation-flocculation process

\begin{tabular}{|c|c|c|c|c|c|c|c|}
\hline OMW origin & Phenols (g/L) & $\mathrm{DCO}(\mathrm{g} / \mathrm{L})$ & Coagulant/flocculant & Dose $(g / L)$ & Phen & $\mathrm{DCO} \%$ & Ref. \\
\hline $\begin{array}{l}\text { Extraction process } \\
\text { Greece ( } 3 \text {-phase) }\end{array}$ & 1.9 & 40.9 & $\mathrm{Ca}(\mathrm{OH})_{2} / \mathrm{PDADMAC}$ & $20 / 1.25$ & 76 & 56 & Iakovides et al. (2014) \\
\hline Greece (W1) (3-phase) & 12.08 & 87.5 & $\mathrm{PAC} / \mathrm{FLOCAN} 23-20$ & $4 / 0.01$ & 45 & 36 & Pelendridou et al. (2014) \\
\hline & & & ASM/ Praestol 2240 & $4 / 0.01$ & 15 & 10 & \\
\hline Greece (W2) (3-phase) & 4.11 & 42.5 & $\mathrm{PAC} / \mathrm{FLOCAN} 23-20$ & $2 / 0.01$ & 34 & 41 & \\
\hline & & & ASM/ Praestol 2240 & $2 / 0.01$ & 22 & 30 & \\
\hline Greece (3-phase) & 1.67 & 43.3 & 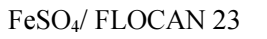 & $6.67 / 0.28$ & 40 & 72 & Papaphilippou et al. (2013) \\
\hline & & & $\mathrm{FeSO}_{4} / \mathrm{FLOCAN} 23$ & $5 / 0.28$ & 30 & 68 & \\
\hline Greece (n.d.) & 3.5 & 61.1 & $\mathrm{FeSO}_{4} / \mathrm{Al}$ & $5 / 0.28$ & 12.5 & 22.5 & Ginos et al. (2006) \\
\hline & & & $\mathrm{FeSO}_{4} / \mathrm{A} 2$ & $5 / 0.28$ & 12.5 & 32.5 & \\
\hline & & & $\mathrm{FeSO}_{4} / \mathrm{K} 1$ & $5 / 0.28$ & 32.5 & 22.5 & \\
\hline & & & $\mathrm{FeSO}_{4} / \mathrm{K} 2$ & $5 / 0.28$ & 32.5 & 27.5 & \\
\hline & & & $\mathrm{FeSO}_{4} / \mathrm{K} 3$ & $5 / 0.28$ & 25 & 22.5 & \\
\hline & & & $\mathrm{FeSO}_{4} / \mathrm{K} 4$ & $5 / 0.28$ & 25 & 25 & \\
\hline & & & $\mathrm{Ca}(\mathrm{OH})_{2} / \mathrm{A} 1$ & $30 / 0.28$ & 55 & 12.5 & \\
\hline & & & $\mathrm{Ca}(\mathrm{OH})_{2} / \mathrm{A} 2$ & $30 / 0.28$ & 55 & 15 & \\
\hline & & & $\mathrm{Ca}(\mathrm{OH})_{2} / \mathrm{K} 1$ & $30 / 0.28$ & 47.5 & 10 & \\
\hline & & & $\mathrm{Ca}(\mathrm{OH})_{2} / \mathrm{K} 2$ & $30 / 0.28$ & 50 & 10 & \\
\hline & & & $\mathrm{Ca}(\mathrm{OH})_{2} / \mathrm{K} 3$ & $30 / 0.28$ & 50 & 10 & \\
\hline & & & $\mathrm{Ca}(\mathrm{OH})_{2} / \mathrm{K} 4$ & $30 / 0.28$ & 60 & 30 & \\
\hline
\end{tabular}


Table 8: Market prices for bulk sales of chemical materials (Sarika et al., 2005; Ginos et al., 2006)

\begin{tabular}{ll}
\hline Chemical materials & Price $€ /$ tonne \\
\hline Coagulants & \\
Lime & 130 \\
$\mathrm{FeCl}_{3}$ & 350 \\
$\mathrm{FeSO}_{4}$ & 150 \\
Polyelectrolyte & \\
Polyaluminum chloride (PAC) & 300 \\
Cationic flocculants & \\
FO-4700 & 2980 \\
FO-4490 & 2800 \\
FO-4350 & 2800 \\
FO-4190 & 2800 \\
Anionic flocculants & \\
FLOCAN 23 & 2500 \\
AN-934 & 2550 \\
Praestol-2240 & 3100 \\
\hline
\end{tabular}

The main advantages of this process over others is its simplicity, low energy consumption, low $\mathrm{CO}_{2}$ emission ( $0.4 \mathrm{~g}$ of $\mathrm{CO}_{2}$ per $\mathrm{kg}$ of $\mathrm{COD}$ removed from waste) (Pelendridou et al., 2014) and low capital cost. As presented in Table 8, the market price of coagulants is very much lower compared to other chemical materials.

Coagulation process has been used for many years as main treatment due to its beneficial. As shown in Table 3, the lime application allowed a significant removal of phenolic compounds at basic $\mathrm{pH}$ (up to 60$70 \%$ reduction of the initial phenolic compound values) and part of the COD $(40-50 \%)$. However, the major limitation of lime is the increase of solution $\mathrm{pH}$ and hardness, the low COD removal capacity typically between $20-50 \%$ and the generation of excessive volumes of sludge. In addition, from Table 4 and several report it is observed that the usage of dual coagulants (acid cracking + inorganic metal coagulants) can give very attractive results in removing COD and phenolic compounds. However, inorganic coagulants application has been reported not worthy in reducing organic matter (up to 10$40 \%$ reduction of the initial COD values). Also, their usage is quite limited nowadays and has been reduced due to several disadvantages. As reported in many studies (Jaouani et al., 2005; Tzoupanos and Zouboulis, 2008; Mert et al., 2010; Otlesa and Seleka, 2012; Alaoui et al., 2016), their usage would cause many important environmental consequences, which are; $\mathrm{pH}$ adjustment before or after treatment, sensitivity to temperature changes, production of large volumes of sludge which will create disposal problem and an increase in metal (e.g., aluminium) concentration in the treated water which may have human health implications (Flaten, 2001; Ward et al., 2006). According to Polizzi et al. (2002; Banks et al., 2006), recent epidemiological, neuropathological and biochemical studies suggest a possible link between the neurotoxicity of aluminium and the pathogenesis of Alzheimer's disease. Other disadvantage include the need for high doses of coagulants because the charge neutralization is not usually sufficient and the inefficient of process towards very fine particles. For these reasons, various studies noticed that coagulation process is only a partial solution and must be used in combination with others treatments as pretreatment or posttreatment because the treated wastewater still has a high load of phenolic compounds and COD.

In this context, many research studies have proved that the real treatment of OMW by coagulation cannot been achieved without combinations of existing technologies such as, advanced oxidation processes (Ginos et al., 2006; Rizzo et al., 2008; Amaral-Silva et al., 2016), aerobic biological treatment (Jaouani et al., 2005; Pelendridou et al., 2014; Chiavola et al., 2010), Fenton processes (Rizzo et al., 2008; Lucas and Peres, 2009; Yazdanbakhsh et al., 2015; Madani et al., 2015; GursoyHaksevenler, Arslan-Alaton, 2014; Michael et al., 2014; Alver et al., 2015; Ioannou-Ttofa et al., 2017), catalytic ozonation (Eren et al., 2015) and membrane processes (Stoller and Chianese, 2006b; 2007; Stoller, 2009).

In order to minimize the drawbacks of coagulation process and enhance the elimination of phenolic compounds and COD from OMW, two processes have been taken into consideration; direct flocculation and coagulation-flocculation processes. Direct flocculation is the physical process of bringing the destabilized particles in contact to form larger flocs that can be more easily removed from suspension. Flocculation is usually used in conjunction with and preceded by coagulation. The process is generally accomplished by slow mixing of the destabilized suspension to provide an opportunity for the particles to come into contact with one another and bridge together. In direct flocculation, the mechanism is attributed to (1) neutralization of the negative charge of colloidal particles and (2) bridging the aggregated destabilized particles together to form flocs (Chong, 2012). An important aspect to be taken into account and reported by Chong (2012) is the use of flocculants at any range of $\mathrm{pH}$ values including acidic, neutral and base medium. The use of high molecular weight polymers could bridge the colloidal particles with loops and tails at any $\mathrm{pH}$ condition. This phenomenon is in contrast with the coagulation process where the complex precipitates of metal hydroxides are only obtained at the desired $\mathrm{pH}$ after addition of coagulant and $\mathrm{pH}$ alteration.

In practice, many studies are promoting the utilization of polyelectrolyte, as flocculants in OMW, more than metal-based coagulants, because they produce large, dense, compact and stronger flocs with good settling characteristic compared to those obtained by coagulation process (Renault et al., 2009; Lee et al., 2014). They can also involve the application of lesser dosage of floculants, less $\mathrm{pH}$ dependent and reduce the residual fraction of unbound metallic compounds (Chang et al., 2005; Gao et al., 2008). In addition, direct flocculation generates less volume of sludge (Hodaifa et al., 2015) because the flocs formed with strong bridging 
mechanism are densed and closely packed. In addition, as the polymers are organic in nature, thus some of the sludge generated is readily for disposal after simple treatment. For this reason, various reports are predicting that the use of polymeric flocculants can reduce the overall treatment cost by $25-30 \%$, in comparison with metallic coagulants treatment (Nozaic et al., 2001). However, although polyelectrolytes find a wide range of applications as flocculants in removing organic matter from industrial wastewater, the potential associated with their use presents numerous disadvantages such as ineffectiveness removal of phenolic compounds and COD (Table 6), high cost (Table 8), less biodegradability and toxicity (Ginos et al., 2006). According to Bolto and Gregory (2007) the normally used anionic and non-ionic polymers are generally of low toxicity, but cationic polyelectrolytes are more toxic, especially to aquatic organisms. In order to improve the efficiency of direct flocculation process, many researchers have studied the development of natural low-cost (bio-flocculants) alternatives to synthetic polyelectrolytes (Rizzo et al., 2008; Renault et al., 2009; Fragoso and Duarte, 2012; Speltini et al., 2016; El Moussaoui et al., 2018). The major advantage of natural polymer is its non-toxicity to the environment and biodegradability. Compared with conventional chemical flocculants, bio-flocculants are safe, fairly shear stable, easily available from reproducible agricultural resources and produce no secondary pollution (Bolto and Gregory, 2007). Not only this, as biopolymers are biodegradable, the sludge can be efficiently degraded by biologic process (Renault et al., 2009). Thus, they have high potential to be applied not only in food and fermentation processes, pharmaceutical, cosmetic, downstream processing but also in water and wastewater treatment as OMW.

On the other hand, the addition of inorganic metal compounds as coagulants and polyelectrolytes as flocculants stimulates the destabilization of colloidal materials and promotes the agglomeration of small particles in large flocs that are able to quickly settle. Regarding treatment mechanism, coagulation-flocculation is based on charge neutralization (coagulation), followed by bridging (flocculation), while in direct flocculation, the charge neutralization and bridging occur concurrently.

Radoiu et al. (2004) studied the combined use of coagulants and flocculants. They reported that the use of flocculants not only can increase the density and the solidity of the flocs formed, it can also reduce the consumption of coagulants and increases the reliability of the work and the throughput capacity of the treatment plan. Other authors found that coagulation-flocculation process could reduce the cost of treatment. However, many studies reported that the combination of various cationic organic coagulants and flocculant agents did not show any significant decrease of COD and phenolic compounds except for lime combination $\left(\mathrm{Ca}(\mathrm{OH})_{2}\right)$
(Table 7). As presented above, the chemical treatment by coagulation-flocculation is not efficient for the reduction of organic materials in OMW. However, this process may be applied to wastewater as postreatment or pretreatment to remove the suspended solids.

\section{Discussion}

According to this literature study, the chemical materials (coagulants, polyelectrolytes, cationic and anionic flocculants) showed interesting results for removal of the organic matter from OMW. However, despite the number of published research papers, the treatment of OMW by coagulation/flocculation processes still limited on laboratory scale and have not been applied on industrial scale, mainly due to the complex nature of the effluent.

There are several strategies and combination techniques concerned by the removal of phenolic compounds and organic charge from OMW that can be proposed and can be summarized as follows:

The treatment of OMW by coagulation and coagulation-flocculation depends mainly to coagulant and flocculants type and dosage, $\mathrm{pH}$, mixing condition, the presence of anionic and cationic minerals and phenolic compounds properties. In most of the article, the reduction of COD and polyphenols at acidic $\mathrm{pH}$ of OMW is very low regardless to the type and dosage coagulants used. In order to increase the removal efficiency, the optimization of $\mathrm{pH}$ parameter is recommended. However, direct flocculation process is workable at any $\mathrm{pH}$ condition.

The important removal of suspended and colloidal matter and mainly phenolic compounds is obtained by lime. Many studies reported that the reduction of phenolic compounds could exceeds $60 \%$. However, the basic $\mathrm{pH}$ of treated effluent and large volume of sludge produced could limit this technique. For this reason, several alternative solutions could be tested. (i) innovative use of sludge as a fuel, a soil conditioner or a building material. (ii) neutralization of basic $\mathrm{pH}$ allows the application of a biologic treatment.

In the case where the aim is to decrease the sludge volume produced, the suitable process to use is coagulation-flocculation. However, the combination of coagulants and flocculants agents not show any significant decrease of the organic matter. Indeed, this process can be applied as pre-treatment to remove the suspended solids.

The applicability of chemical coagulants for OMW treatment can be more efficient if it is preceded by a pretreatment process such as natural evaporation in ambient air with the use of solar energy in evaporation ponds or storage lakes (lagoons).

The coagulation/flocculation treatment of OMW cannot be achieved without combination with another treatment process in which to further degrade the organic 
compounds to lower level. The best combination can be realized by comprising filtration of raw OMW on two successive Olive Stone (OS) filters. The results show that the use of OS filter leads to a higher removal of total suspended solids $(82.5 \%)$ and fatty matter $(73.8 \%)$ from the raw OMW (Enaime et al., 2018).

\section{Conclusion}

OMW is produced in a limited period and in large quantities and their chemical and physical characteristics vary according to cultivars, harvesting time, type of olives and the extraction technology (pressing or centrifuging). For all above-mentioned reasons, flexible and efficient treatment plants are necessary.

In this review, a focus on the relevant state-of-the art on physico-chemical processes for the treatment of OMW is presented, including coagulation, direct flocculation and coagulation-flocculation. Each treatment process has its advantages as well as drawbacks. In terms of effectiveness, all research studies reported that coagulation process using mineral and inorganic polymeric coagulants and acid cracking, direct flocculation with synthetic organic polymers and coagulation-flocculation did not show any significant removal of COD and phenolic compounds from OMW.

In this sense, it is evident from the consideration above that a single process cannot offer an efficient in removing of phenolic compounds and COD and viable solution to the problem. For these reasons, the combination of coagulation, direct flocculation and coagulation-flocculation with existing technologies (advanced oxidation processes, aerobic and anaerobic biological, Fenton processes, adsorption, infiltrationpercolation and membrane processes) are recommended as pre-treatment or post-treatment by various authors.

\section{Acknowledgment}

The authors would like to thank the National School of Applied Sciences, Chouaïb Doukkali University in El Jadida, Morocco for funding this work.

\section{Author's Contributions}

Mounia Achak: Contributed to analyzing, discussing and interpreting the data; Writing the paper and checking the final review.

Fatima Elayadi: Contributed to studying literature research of coagulation process, revising paper and addressing the corrections.

Wafaa Boumya: Contributed to studying literature research of coagulation and flocculation processes and checking the final review.

\section{Ethics}

This article is original and contains unpublished study. The corresponding author confirms that all of the other authors have read and approved the manuscript and no ethical issues involved.

\section{References}

Achak, A., N. Ouazzani, A. Yaacoubi and L. Mandi, 2008. Caractérisation des margines issues d'une huilerie moderne et essai de leur traitement par coagulation-floculation par la chaux et le sulfate d'aluminium. Sci. l'Eau, 21: 53-57.

DOI: 10.7202/017930ar

Achak, M., A. Hafidi, L. Mandi and N. Ouazzani, 2014. Removal of phenolic compounds from olive mill wastewater by adsorption onto wheat bran. Desalinat. Water Treatment, 52: 2875-2885.

DOI: 10.1080/19443994.2013.819166

Achak, M., A. Hafidi, N. Ouazzani, S. Sayadi and L. Mandi, 2009a. Low cost biosorbent "banana peel" for the removal of phenolic compounds from olive mill wastewater: Kinetic and equilibrium studies. J. Hazardous Mater., 166: 117-125.

DOI: $10.1016 /$ j.jhazmat.2008.11.036

Achak, M., L. Mandi and N. Ouazzani, 2009b. Removal of organic pollutants and nutrients from olive mill wastewater by sand filter. J. Environ. Manage., 90: 2771-2779. DOI: 10.1016/j.jenvman.2009.03.012

Afoufou, F., N. Guesbaya and S. Achour, 2007. The effect of natural water mineralization on aromatic organics removal by coagulation-flocculation. Courrier Savoir, 08: 75-81.

Agabo García, C. and G. Hodaifa, 2017. Real olive oil mill wastewater treatment by photo-Fenton system using artificial ultraviolet light lamps. J. Cleaner Product., 162: 743-753.

DOI: $10.1016 /$ j.jclepro.2017.06.088

Aharonov-Nadborny, R., L. Tsechansky, M. Raviv and E.R. Graber, 2018. Mechanisms governing the leaching of soil metals as a result of disposal of olive mill wastewater on agricultural soils. Sci. Total Environ., 630: 1115-1123. DOI: $10.1016 /$ j.scitotenv.2018.02.270

Ahmad, A.L., S.S. Wong, T.T. Teng and A. Zuhairi, 2008. Improvement of alum and $\mathrm{PACl}$ coagulation by Polyacrylamides (PAMs) for the treatment of pulp and paper mill wastewater. Chem. Eng. J., 137: 510-517. DOI: 10.1016/j.cej.2007.03.088

Ahmad, T., M. Rafatullah, A. Ghazali, O. Sulaiman and R. Hashim, 2011. Oil palm biomasses based adsorbents for the removal of water pollutants-a review. J. Environ. Sci. Health. Part C, 29: 177-222. DOI: $10.1080 / 10590501.2011 .601847$ 
Aktas, E.S., I. Sedat and E. Lale, 2001. Characterization and lime treatment of olive mill wastewater. Wat. Res., 35: 2336-2340.

DOI: $10.1016 / \mathrm{S} 0043-1354(00) 00490-5$

Aktas, O. and F. Cecen, 2007. Adsorption, desorption and bioregeneration in the treatment of 2chlorophenol with activated carbon. J. Hazard. Mater., 141: 769-777.

DOI: 10.1016/j.jhazmat.2006.07.050

Alaoui Slimani, N., A. El Laghdach, M. Stitou and A. Bakkali, 2016. Treatment and valorization of olive mill wastewaters. Mediterranean J. Chem., 5: 458-464.

Alba, J., 1994. Nuevas tecnologías para la obtención del aceite de oliva. Fruticultura Profes. Suplemento., 62: 85-95.

Alburquerque, J.A., J. Gonzaélvez, D. Garciéa and J. Cegarra, 2004. Agrochemical characterisation of "alperujo", a solid by-product of the two-phase centrifugation method for olive oil extraction. Bioresour. Technol., 91: 195-200. DOI: $10.1016 / \mathrm{S} 0960-8524(03) 00177-9$

Ali, A. and K. Saeed, 2015. Phenol removal from aqueous medium using chemically modified banana peels as low-cost adsorbent. Desalin. Water Treat., 57: $11242-11254$.

DOI: $10.1080 / 19443994.2015 .1041057$

Aliakbarian, B., A.A. Casazza and P. Perego, 2015. Kinetic and isotherm modelling of the adsorption of phenolic compounds from olive mill wastewater onto activated carbon. Food Technol. Biotechnol., 53: 207-214. DOI: $10.17113 / \mathrm{ftb} .53 .02 .15 .3790$

Al-Malah, K., M.O.J. Azzam and N.I. Abulail, 2000. Olive Mills Effluent (OME) wastewater posttreatment using activated clay. Separ. Purif. Technol., 20: 225-234.

DOI: 10.1016/S1383-5866(00)00114-3

Alver, A., E. Bastürk, A. Kılıc and M. Karatas, 2015. Use of advance oxidation process to improve the biodegradability of olive oil mill effluents. Process Saf. Environ. Protect., 98: 319-324.

DOI: $10.1016 /$ j.psep.2015.09.002

Amaral-Silva, N., R.C. Martins, S. Castro-Silva and R.M. Quinta-Ferreira, 2016. Integration of traditional systems and advanced oxidation process technologies for the industrial treatment of olive mill wastewaters, Environ. Technol., 37: 2524-2535. DOI: $10.1080 / 09593330.2016 .1153158$

Amor, C., M.S. Lucas, J. García, J.R. Dominguez, J.B. De Heredia and J.A. Peres, 2015. Combined treatment of olive mill wastewater by Fenton's reagent and anaerobic biological process. J. Environ. Sci. Health, Part A, 50: 161-168.

Angelidaki, I. and B.K. Ahring, 1992. Effects of free long-chain fatty acids on thermophilic anaerobic digestion. Applied Microbiol. Biotechnol., 37: 808812. DOI: $10.1007 / \mathrm{BF} 00174850$
Assas, N., L. Ayed, L. Marouani and M. Hamdi, 2002. Decolorization of fresh and stored-black olive mill wastewaters by Geotrichum candidum Original. Process Biochem., 38: 361-365.

DOI: 10.1016/S0032-9592(02)00091-2

Ayoub, S., 2006. Olive industry in Jordan. Proceeding of the 2nd International Seminar on Olivebioteq, Nov. 5-10, Marsala, Italy, pp: 65-71.

Azbar, N., K.E. Tugba and C. Cokay, 2008. Improvement in anaerobic degradation of Olive Mill Effluent (OME) by chemical pretreatment using batch systems. Biochem. Eng. J., 38: 379-383. DOI: $10.1016 /$ j.bej.2007.08.005

Azzam, M.O.J., 2018. Olive mills wastewater treatment using mixed adsorbents of volcanic tuff, natural clay and charcoal. J. Environ. Chem. Eng., 6: 2126-2136. DOI: $10.1016 /$ j.jece.2018.03.009

Azzam, M.O.J., K.I. Al-Malah, N.I. and Abu-Lail, 2004. Dynamic post-treatment response of olive mill effluent wastewater using activated carbon. J. Environ. Sci. Health, 39: 269-280. DOI: $10.1081 /$ ESE-120027383

Babel, S. and T.A. Kurniawan, 2003. Low-cost adsorbents for heavy metals uptake from contaminated water: A review. J. Hazard Mater. B, 97: 219-219. DOI: 10.1016/S0304-3894(02)00263-7

Bacha, N. and S. Achour, 2015. Influence de paramètres réactionnels sur la stœchiométrie sulfate d'aluminium/matière organique naturelle en eau distillée. Larhyss J., 21: 151-158.

Bahadori, A., M. Clark and B. Boyd, 2013. Essentials of Water Systems Design in the Oil, Gas and Chemical Processing Industries. 1st Edn., Springer, Berlin, ISBN-10: 1461465168, pp: 102.

BaiChuan, C., G. BaoYu, X. ChunHua. F. Ying and I. Xin, 2010. Effects of $\mathrm{pH}$ on coagulation behavior and floc properties in Yellow River water treatment using ferric-based coagulants. Environ. Chem., 55: 1382-1387.

Balasubramanian, J., P.C. Sabumon, J.U. Lazar and R. Ilangovan, 2006. Reuse of textile effluent treatment plant sludge in building materials. Waste Manage., 26: 22-28. DOI: 10.1016/j.wasman.2005.01.011

Banks, W.A., M.L. Niehoff, D. Drago and P. Zatta, 2006. Aluminum Complexing enhances amyloid protein penetration of blood-brain barrier. Brain Res., 1116: 215-221. DOI: $10.1016 /$ j.brainres.2006.07.112

Barbera, A.C., C. Maucieri, A. Ioppolo, M. Milani and V. Cavallaro, 2014. Effects of olive mill wastewater physico-chemical treatments on polyphenol abatement and Italian ryegrass (Lolium multiflorum L.) germinability. Water Res., 52: 275-281.

DOI: 10.1016/j.watres.2013.11.004 
Barbera, A.C., C. Maucieri, V. Cavallaro, A. Ioppolo and G. Spagna, 2013. Effects of spreading olive mill wastewater on soil properties and crops, a review. Agric. Water Manag., 119: 43-53.

DOI: $10.1016 /$ j.agwat.2012.12.009

Beccari, M., M. Majone and L. Torrisi, 1998. Tworeactor system with partial phase separation for anaerobic treatment of olive oil mill effluents. Water Sci. Technol., 38: 53-60. DOI: $10.2166 /$ wst. 1998.0580

Belaid, C., M. Khadraoui, S. Mseddi, M. Kallel and B. Elleuch et al., 2013. Electrochemical treatment of olive mill wastewater: treatment extent and effluent phenolic compounds monitoring using some uncommon analytical tools. J. Environ. Sci., 25: 220-230. DOI: 10.1016/S1001-0742(12)60037-0

Belaqziz, M., A. El-Abbassi, E. K. Lakhal, E. Agrafioti and C.M. Galanakis, 2016. Agronomic application of olive mill wastewater: Effects on maize production and soil properties. J. Environ. Manage., 171: 158-165. DOI: 10.1016/j.jenvman.2016.02.006

Beltrán-Heredia, J., J. Torregrosa, J. Garcia, J.R. Domínguez and J.C. Tierno, 2001. Degradation of olive mill wastewater by the combination of Fenton's reagent and ozonation processes with an aerobic biological treatment Water Sci. Technol., 44: 103-108. DOI: 10.2166/wst.2001.0262

Bernhardt, H., O. Hoyer and B. Lusse, 1986. The addition of calcium to reduce the impairment of flocculation by algogenic organic matter, Z. Wasser. Abwasser. Forsch, 19: 219-228.

Boari, G., A. Brunetti, R. Passino and A. Rozzi, 1984. Anaerobic digestion of olive oil mill wastewaters. Agric. Wastes, 10: 161-175. DOI: 10.1016/0141-4607(84)90057-X

Bohuslav Dobias, H.S., 2005. Coagulation and Flocculation. 2nd Edn., CRC Press, Taylor and Francis Group, USA.

Bolto, B. and J. Gregory, 2007. Organic polyelectrolytes in water treatment. Water Res., 41: 2301-2324. DOI: 10.1016/j.watres.2007.03.012

Bolto, B.A., D.R. Dixon, R.J. Eldridge and S.J. King, 1998. The Use of Cationic Polymers as Primary Coagulants in Water Treatment. In: Chemical Water and Wastewater Treatment V, Hahn, H.H., E. Hoffmann and H. Odegaard (Eds.), Springer, Berlin Heidelberg.

Boukhoubza, F., A. Jail, F. Korchi, L. Loukili Idrissi and H. Hannache et al., 2009. Application of lime and calcium hypochlorite in the dephenolisation and discolouration of olive mill wastewater. J. Environ. Manage., 91: 124-132.

DOI: 10.1016/j.jenvman.2009.07.004

Bratby, J., 2007. Coagulants. In: Coagulation and Flocculation in Water and Wastewater Treatment, IWA Publishing, London, pp: 50-68.
Brostow, W., H.E.H. Lobland and R.P. SagarPalSingh, 2009. Polymeric flocculants for wastewater and industrial effluent treatment. J. Mater. Educ., 31: 157-166.

Canizares, P., J. Lobato, R. Paz, M. Rodrigo and C. Saez, 2007. Advanced oxidation processes for the treatment of olive-oil mills wastewater. Chemosphere, 67: 832-838.

DOI: $10.1016 /$ j.chemosphere.2006.10.064

Canizares, P., R. Paz, C. Saez and M.A. Rodrigo, 2009. Costs of the electrochemical oxidation of wastewaters: A comparison with ozonation and Fenton oxidation processes. J. Environ. Manage., 90: 410-420. DOI: 10.1016/j.jenvman.2007.10.010

Cao, B., B. Gao, X. Liu, M. Wang and Z. Yang et al., 2011. The impact of $\mathrm{pH}$ on floc structure characteristic of polyferric chloride in a low DOC and high alkalinity surface water treatment. Water Res., 45: 6181-6188.

DOI: $10.1016 /$ j.watres.2011.09.019

Cassano, A., C. Conidi and E. Drioli, 2011. Comparison of the performance of UF membranes in olive mill wastewaters treatment. Water Res., 45: 3197-3204. DOI: 10.1016/j.watres.2011.03.041

Chaari, L., N. Elloumi, S. Mseddi, K. Gargouri and B. Ben Rouina et al., 2015. Changes in soil macronutrients after a long-term application of olive mill wastewater. J. Agric. Chem. Environ., 4: 1-13. DOI: $10.4236 /$ jacen.2015.41001

Chang, E.E., P.C. Chiang, W.Y. Tang, S.H. Chao and H.J. Hsing, 2005. Effects of polyelectrolytes on reduction of model compounds via coagulation. Chemosphere, 58: 1141-1150. DOI: 10.1016/j.chemosphere.2004.08.008

Chatzisymeon, E., E. Diamadopoulos and D. Mantzavinos, 2009. Effect of key operating parameters on the non-catalytic wet oxidation of olive mill wastewaters. Water Sci. Technol., 59: 2509-2518. DOI: 10.2166/wst.2009.321

Cheng, W.P. and F.H. Chi, 2002. A study of coagulation mechanisms of polyferric sulfate reacting with humic acid using a fluorescence-quenching method. Water Res., 36: 4583-4591. DOI: 10.1016/S0043-1354(02)00189-6

Chiavola, A., G. Farabegoli and E. Rolle, 2010. Combined biological and chemical-physical process for olive mill wastewater treatment. Desalinat. Water Treat., 23: 135-140. DOI: $10.5004 /$ dwt.2010.1987

Chiavola, A., G. Farabegoli and F. Antonetti, 2014. Biological treatment of olive mill wastewater in a sequencing batch reactor. Biochem. Eng. J., 85: 71-78. DOI: 10.1016/j.bej.2014.02.004 
Chong, M., 2012. Direct Flocculation Process for Wastewater Treatment. In: Advances in Water Treatment and Pollution Prevention, Sharma, S.K. and R. Sanghi (Eds.), Springer, Netherlands, pp: 201-230. DOI: 10.1007/978-94-007-4204-8 8

Clément, M., R. Seux and B. Moussa, 1983. Études des facteurs déterminant la fuite en aluminium dans les eaux d'alimentation préparées à partir d'eaux clarifiées par des sels de ce métal. Trib. Cebedeau., 480: 469-481.

Crittenden, J.C., R.R. Trussel, D.W. Hand, K.J. Howe and G. Tchobanoglous, 2005. Coagulation, Mixing and Flocculation. In: Water Treatment: Principles and Design, John Wiley and Sons, New Jersey, pp: 643-779.

Danellakis, D., I. Ntaikou, M. Kornaros and S. Dailianis, 2011. Olive oil mill wastewater toxicity in the marine environment: Alterations of stress indices in tissues of mussel Mytilus galloprovincialis. Aquat. Toxicol., 101: 358-366.

DOI: $10.1016 /$ j.aquatox.2010.11.015

Davididou, K., E. Chatzisymeon, L. Perez-Estrada, I. Oller and S. Malato, 2018. Photo-Fenton treatment of saccharin in a solar pilot compound parabolic collector: Use of olive mill wastewater as iron chelating agent, preliminary results. J. Hazardous Mater. DOI: 10.1016/j.jhazmat.2018.03.016

DellaGreca, M., L. Previtera, F. Temussi and A. Zarrelli, 2004. Low-molecular-weight componentsof olive oilmill waste-waters. Phytochem. Anal., 15: 184-188. DOI: $10.1002 /$ pca.766

Dermeche, S., M. Nadoura, C. Larroche, F. Moulti-Mati and P. Michaud, 2013. Olive mill wastes: biochemical characterizations and valorization strategies. Process Biochem., 48: 1532-1552.

DOI: 10.1016/j.procbio.2013.07.010

Dhaouadi, H. and B. Marrot, 2008. Olive mill wastewater treatment in a membrane bioreactor: Process feasibility and performances, Chem. Eng. J., 145: 225-231. DOI: 10.1016/j.cej.2008.04.017

Di Bene, C., E. Pellegrino, M. Debolini, N. Silvestri and E. Bonari, 2013. Short- and long-term effects of olive mill wastewater land spreading on soil chemical and biological properties. Soil Biol. Biochem., 56: 21-30.

DOI: 10.1016/j.soilbio.2012.02.019

Di Giovacchino, L., 1996. Influence of extraction systems on olive oil quality. Olivae, 63: 52-63.

Di Serio, M.G., B. Lanza, M.R. Mucciarella, F. Russi and E. Iannucci et al., 2008. Effects of olive mill wastewater spreading on the physico-chemical and microbiological characteristics of soil. Int. Biodeteriorat. Biodegradat., 62: 403-407.

DOI: $10.1016 /$ j.ibiod.2008.03.006
Dominguez, J.R., T. González, H.M. Garcían, F. Sánchez-Lavado and J. Beltrán de Heredia, 2007. Aluminium sulfate as coagulant for highly polluted cork processing wastewaters: Removal of organic matter. J. Hazardous Mater., 148: 15-21. DOI: 10.1016/j.jhazmat.2007.05.003

Doula, M., F. Tinivella, L. Luis Moreno Ortego, V. Kavvadias and A. Sarris et al., 2012. Good Practices for the Agronomic use of Olive Mill Wastes. In: Strategies to Improve and Protect Soil Quality from the Disposal of Olive Oil Mill Wastes in the Mediterranean, Doula, M. (Ed.), PROSODOL, Athens.

Duan, J. and J. Gregory, 2003. Coagulation by hydrolysing metal salts. Adv. Colloid Interface Sci., 100-102: 475- 502. DOI: 10.1016/S0001-8686(02)00067-2

Ebeling, J.M., C.F. Welsh and K.L. Rishel, 2006. Performance evaluation of an inclined belt filter using coagulation/flocculation aids for the removal of suspended solids and phosphorus from microscreen backwash effluent. Aquacultural Eng., 35: 61-77. DOI: 10.1016/j.aquaeng.2005.08.006

Edwards, G A. and A. Amirtharajah, 1985. Removing color caused by humic acids. J. Am. Water Works Assoc., 77: 50-57. DOI: 10.1002/j.1551-8833.1985.tb05508.x

El Moussaoui, T., Y. Jaouad, L. Mandi, B. Marrot and N. Ouazzani, 2018. Biomass behaviour in a conventional activated sludge system treating olive mill wastewater. Environ. Technol., 39: DOI: $10.1080 / 09593330.2017 .12968992018$

El-Abbassi, A., M. Khayet and A. Hafidi, 2011. Micellar enhanced ultrafiltration process for the treatment of olive mill wastewater. Water Res., 45: 4522-4530. DOI: 10.1016/j.watres.2011.05.044

Enaime, G., A. Baçaoui, A. Yaacoubi, M. Wichern and M. Lübken, 2018. Olive mill wastewater pretreatment by combination of filtration on olive stone filters and coagulation-flocculation. Environ. Technol. DOI: 10.1080/09593330.1439106

Eren, O., S. Gul, E. Kusvuran, K. Cellat and F.M. Ertosun, 2015. Treatment of olive mill wastewater by catalytic ozonation using activated carbon prepared from olive stone by KOH. Asian J. Chem., 27: 4106-4110. DOI: 10.14233/ajchem.2015.19106

Filidei, S., G. Masciandaro and B. Ceccanti, 2003. Anaerobic digestion of olive mill effluent: Evaluation of wastewater organic load and phytotoxicity reduction. Water Air Soil Pollut., 145: 79-94. DOI: 10.1023/A:1023619927495

Fitzpatrick, C.S.B., E. Fradin and J. Gregory, 2004. Temperature effects on flocculation, using different coagulants. Water Sci. Technol., 50: 171-175. DOI: $10.2166 /$ wst.2004.0710

Flaten, T.P., 2001. Aluminium as a risk factor in Alzheimer's disease, with emphasis on drinking water. Brain Res. Bull., 55: 187-196. DOI: 10.1016/S0361-9230(01)00459-2 
Fragoso, R. and E. Duarte, 2012. Reuse of drinking water treatment sludge for olive oil wastewater treatment. Water Sci. Technol., 66: 887-894. DOI: $10.2166 /$ wst.2012.267

Frascari, D., A.E.M. Bacca, F. Zama, L. Bertin and F. Fava et al., 2016. Olive mill wastewater valorisation through phenolic compounds adsorption in a continuous flow column. Chem. Eng. J., 283: 293-303. DOI: 10.1016/j.cej.2015.07.048

Galiatsatou, P., M. Metaxas, D. Arapoglou and V. Kasselouri-Rigopoulou, 2002. Treatment of olive mill waste water with activated carbons from agricultural by-products. Waste Manage., 22: 803-812. DOI: 10.1016/S0956-053X(02)00055-7

Gao, B.Y., Y. Wang, Q.Y. Yue, J.C. Wei and Q. Li, 2008. The size and coagulation behavior of a novel composite inorganiceorganic coagulant. Sep. Purif. Technol., 62: 544-550.

DOI: 10.1016/j.seppur.2008.02.023

Gernjak, W., M. Maldonado, S. Malato, J. Caceres and T. Krutzler et al., 2004. Pilot-plant treatment of Olive Mill Wastewater (OMW) by solar $\mathrm{TiO}_{2}$ photocatalysis and solar photo-Fenton. Sol. Energy, 77: 567-572. DOI: 10.1016/j.solener.2004.03.030

Ginos, A., M. Thrassyvoulos and M. Dionissios, 2006. Treatment of olive mill effluents by coagulationflocculation-hydrogen peroxide oxidation and effect on phytotoxicity. J. Hazardous Mater. B, 133: 135-142. DOI: 10.1016/j.jhazmat.2005.10.024

Gocer, S., B.O.M. Eskikaya, A. Kozak, Duyar and V. Akgul et al., 2017. Optimization of acid cracking method for olive mill wastewater pre-treatment acid cracking method for olive mill wastewater. Proceedings of 32nd Research World International Conference, Jul. 22-23, Istanbul, Turkey.

Gonçalves, M.R., J. Correia and I.P. Marques, 2012a. Electrochemical mineralization of anaerobic digested olive mill wastewater. Water Res., 46: 4217-4225. DOI: 10.1016/j.watres.2012.05.019

Gonçalves, M.R., P. Freitas and I.P. Marques, 2012b. Bioenergy recovery from olive mill effluent in a hybrid reactor. Biomass Bioenergy, 39: 253-260. DOI: 10.1016/j.biombioe.2012.01.014

González-González, A. and F. Cuadros, 2015. Effect of aerobic pretreatment on anaerobic digestion of Olive Mill Wastewater (OMWW): An ecoefficient treatment. Food Bioprod. Process., 95: 339-345. DOI: $10.1016 /$ j.fbp.2014.10.005

Greenland, D.J., 1971. Interactions between humic and fulvic acids and clays. Soil Sci., 111: 34-41. DOI: 10.1097/00010694-197101000-00004

Gregory, J. and J.M. Duan, 2001. Hydrolyzing metal salts as coagulants. Pure Appl. Chem., 73: 2017-2026. DOI: $10.1351 /$ pac200173122017
Guigui, C., J.C. Rouch, L. Durand-Bourlier, V. Bonnelye and P. Aptel, 2002. Impact of coagulation conditions on the in-line coagulation/UF process for drinking water production, Desalination, 147: 95-100. DOI: 10.1016/S0011-9164(02)00582-9

Gupta, H. and B. Gupta, 2016. Adsorption of polycyclic aromatic hydrocarbons on banana peel activated carbon. Desalin. Water Treat., 57: 9498-9509. DOI: $10.1080 / 19443994.2015 .1029007$

Gursoy-Haksevenler, H. and I. Arslan-Alaton, 2014. Treatment of olive mill wastewater by chemical processes: Effect of acid cracking pretreatment. Water Sci. Technol., 69: 1453-1461. DOI: $10.2166 /$ wst.2014.042

Gursoy-Haksevenler, H. and I. Arslan-Alaton, 2016. UV fluorescence, FTIR and GC-MS analyses and resin fractionation procedures as indicators of the chemical treatability of olive mill wastewater. Desalinat. Water Treatment, 57: 2372-2382.

DOI: $10.1080 / 19443994.2014 .992979$

Hahn, H., E. Hofmann and H. Odegaard, 2002. Chemical water and wastewater treatment VIII. IWA Publishing, London.

Hamdi, M., 1991a. Effects of agitation and pretreatment on the batch anaerobic digestion of olive mill wastewater. Bioresour. Technol., 36: 173-178. DOI: 10.1016/0960-8524(91)90176-K

Hamdi, M., 1991b. Nouvelle conception d'un procédé de dépollution biologique des margines, effluents liquides de l'extraction de l'huile d'olive. Provence University, Marseille, France.

Hamdi, M., 1993. Future prospects and constraints of olive mill wastewaters use and treatment: A review. Bioprocess Eng., 8: 209-214. DOI: $10.1007 /$ BF00369831

Hanafi, F., M. Mountadar, S. Etahiri, M. Fekhaoui and O. Assobhei, 2013. Biodegradation of toxic compounds in olive mill wastewater by a newly isolated potent strain: Aspergillus niger van Tieghem. J. Water Resource Protect., 5: 768-774. DOI: $10.4236 /$ jwarp.2013.58078

Hanifi, S. and I. El Hadrami, 2008. Phytotoxicity and fertilizing potential of olive mill wastewater for maize cultivation. Agron. Sustain. Dev., 28: 313-319. DOI: 10.1051/agro:2007047

Hattab, A. and M. Bagane, 2016. Treatment of olive mill wastewater by coagulation flocculation and oxidation. J. Chem. Pharm. Res., 8: 218-223.

Hecini, L. and S. Achour, 2014. Coagulationflocculation by aluminum sulfate of organic phenolic compounds and effect of calcium and magnesium salts. Revue des Sciences de l'Eau, 27: 271-280. DOI: 10.7202/1027810ar 
Henderson, R., E. Sharp, P. Jarvis, S. Parsons and B. Jefferson, 2006. Identifying the linkage between particle characteristics and understanding coagulation performance. Water Sci. Technol., 6: 31-38. DOI: 10.2166/ws.2006.005

Hodaifa, G., J.A., Páez, C. Agabo, E. Ramos and J.C. Gutiérrez et al., 2015. Flocculation on the treatment of olive oil mill wastewater: Pretreatment. Int. J. Chem. Molecular Nuclear, 9: 645-650.

Hodaifa, G., J.M. Ochando-Pulido, S. Ben-Driss-Alami, S. Rodriguez-Vives and A. Martinez-Ferez, 2013. Kinetic and thermodynamic parameters of iron adsorption onto olive stones. Ind. Crop. Prod., 49: 526-534. DOI: 10.1016/j.indcrop.2013.05.039

$\mathrm{Hu}$, W.C., C.D. Wu, A.Y. Jia and F. Chen, 2015. Enhanced coagulation for treating slightly polluted algae-containing raw water of the Pearl River combining ozone preoxidation with Polyaluminum Chloride (PAC). Desal. Water Treat., 56: 16981703. DOI: $10.1080 / 19443994.2014 .954003$

Iakovides, I., A. Pantziaros, D. Zagklisa and C. Paraskeva, 2014. Effect of electrolytes/polyelectrolytes on the removal of solids and organics from olive mill wastewater. J. Chem. Technol. Biotechnol., 91: 204-211. DOI: $10.1002 /$ jctb.4563

Ingole, R.S., D.H. Lataye and P.T. Dhorabe, 2017. Adsorption of phenol onto banana peels activated carbon. KSCE J. Civ. Eng., 21: 100-110.

DOI: $10.1007 / \mathrm{s} 12205-016-0101-9$

Ioannou-Ttofa, L., I. Michael-Kordatou, S.C. Fattas, A. Ribeiro and M. Rusan et al., 2017. Treatment efficiency and economic feasibility of biological oxidation, membrane filtration and separation processes and advanced oxidation for the purification and valorization of olive mill wastewater. Water Res., 114: 1-13. DOI: $10.1016 /$ j.watres.2017.02.020

IOC, 2016. International Olive Council.

IOC, 2017. International Olive Council.

Jaouani, A., M. Vanthournhout and M.J. Penninckx, 2005. Olive oil mill wastewater purification by combination of coagulation-flocculation and biological treatments. Environ. Technol., 26: 633-641. DOI: $10.1080 / 09593330.2001 .9619503$

Jarboui, R., B. Hadrich, N. Gharsallah and E. Ammar, 2009. Olive mill wastewater disposal in evaporation ponds in Sfax (Tunisia): Moisture content effect on microbiological and physical chemical parameters. Biodegradation, 20: 845-858.

DOI: $10.1007 / \mathrm{s} 10532-009-9272-0$

Jarboui, R., M. Chtourou, C. Azri, N. and E. Ammar, 2010. Time-dependent evolution of olive mill wastewater sludge organic and inorganic components and resident microbiota in multi-pond evaporation system. Bioresource Technol., 101: 5749-5758. DOI: 10.1016/j.biortech.2010.02.069
Jarvis, P., B. Jefferson and S.A. Parsons, 2006. Floc structural characteristics using conventional coagulation for a high doc, low alkalinity surface water source. Water Res., 40: 2727-2737. DOI: $10.1016 /$ j.watres.2006.04.024

Jiang, J.Q. and N.J.D. Graham, 1996. Enhanced coagulation using $\mathrm{Al} / \mathrm{Fe}(\mathrm{III})$ coagulants: Effect of coagulant chemistry on the removal of color-causing NOM. Environ. Technol., 17: 937-950. DOI: $10.1080 / 09593330.1996 .9618422$

Jiang, Y., J.E. Goodwill, J.E. Tobiason and D.A. Reckhow, 2016. Impacts of ferrate oxidation on natural organic matter and disinfection byproduct precursors. Water Res., 96: 114-125. DOI: $10.1016 /$ j.watres.2016.03.052

Julien, F., B. Gueroux and M. Mazet, 1994. Comparaison de l'élimination de molécules organiques par coagulation-floculation et par adsorption sur flocs d'hydroxyde métallique préformés. Water Res., 28: 2567-2574. DOI: 10.1016/0043-1354(94)90075-2

Justino, C.I., K. Duarte, F. Loureiro, R. Pereira and S.C. Antunes et al., 2009. Toxicity and organic content characterization of olive oil mill wastewater undergoing a sequential treatment with fungi and photo-Fenton oxidation. J. Hazardous Mater., 172: 1560-1572. DOI: 10.1016/j.jhazmat.2009.08.028

Kallel, M., C. Belaid, T. Mechichi, M. Ksibi and B. Elleuch, 2009. Removal of organic load and phenolic compounds from olive mill wastewater by Fenton oxidation with zero-valent iron. Chem. Eng. J., 150: 391-395. DOI: 10.1016/j.cej.2009.01.017

Karaouzas, I., N.T. Skoulikidis, U. Giannakou and T.A. Albanis, 2011. Spatial and temporal effects of olive mill wastewaters to stream macroinvertebrates and aquatic ecosystems status. Water Res., 45: 6334-6346. DOI: 10.1016/j.watres.2011.09.014

Keren, Y., M. Borisover, G.E. Schaumann, D. Diehl and $\mathrm{N}$. Tamimi et al., 2017. Land disposal of olive mill wastewater enhances ability of soil to sorb diuron: Temporal persistence and the effects of soil depth and application season. Agric. Ecosyst. Environ., 236: 43-51. DOI: 10.1016/j.agee.2016.11.013

Kestioglu, K., Y. Taner and A. Nuri, 2005. Feasibility of physico-chemical treatment and Advanced Oxidation Processes (AOPs) as a means of pretreatment of Olive Mill Effluent (OME). Process Biochem., 40: 2409-2416.

DOI: $10.1016 /$ j.procbio.2004.09.015

Khoufi, S., F. Aloui and S. Sayadi, 2007. Treatment of olive oil mill wastewater by combined process electroFenton reaction and anaerobic digestion. Water Res., 40: 2007-2016. DOI: 10.1016/j.watres.2006.03.023

Khoufi, S., F. Aloui and S. Sayadi, 2009. Pilot scale hybrid process for olive mill wastewater treatment and reuse. Chem. Eng. Process. Process Intensif., 48: 643-650. DOI: 10.1016/j.cep.2008.07.007 
Kiliç, M.Y., K. Kestuoglu and G. Kaya, 2009. Physicochemical Treatability of Olive Mill Wastewater (OMW). J. Natural Applied Sci., 13: 271-271.

Kissi, M., 2002. Étude des eaux résiduaires des huileries d'olives (margines): Caractérisation et traitement. Thèse de doctorat, faculté des sciences El Jadida, Maroc.

Kissi, M., M. Mountadar, O. Assobhei, E. Gargiulo and G. Palmieri et al., 2001. Roles of two white-rot basidiomycete fungi in discolouration and detoxication of olive mill waste water. Applied Microbiol. Biotechnol., 57: 221-226.

DOI: $10.1007 / \mathrm{s} 002530100712$

Kong, H., S.C. Cheu, N.S. Othman, S.T. Song and N. Saman et al., 2016. Surfactant modification of banana trunk as low-cost adsorbents and their high benzene adsorptive removal performance from aqueous solution. RSC Adv., 6: 24738-24751. DOI: 10.1039/C6RA00911E

Kontos, S.S., F.K. Katrivesis, T.C. Constantinou, C.A. Zoga and I.S. Ioannou et al., 2018. Implementation of membrane filtration and melt crystallization for the effective treatment and valorization of olive mill wastewaters. Separat. Purificat. Technol., 193: 103-111. DOI: 10.1016/j.seppur.2017.11.005

Kontos, S.S., I.C. Iakovides, P.G. Koutsoukos and C.A. Paraskeva, 2016. Isolation of purified high added value products from olive mill wastewater streams through the implementation of membrane technology and cooling crystallization process. Transactions, 47: 337-342.

Korshin, G., C. Chow, R. Fabris and M. Drikas, 2009. Absorbance spectroscopy-based examination of effects of coagulation on the reactivity of fractions of natural organic matter with varying apparent molecular weights. Water Res., 43: 1541-1548. DOI: 10.1016/j.watres.2008.12.041

Kougias, P.G., T.A. Kotsopoulos and G.G. Martzopoulos, 2014. Effect of feedstock composition and organic loading rate during the mesophilic co-digestion of olive mill wastewater and swine manure. Renew. Energy, 69: 202-207. DOI: 10.1016/j.renene.2014.03.047

Lee, C.S., J. Robinsonb and M. Chonga, 2014. A review on application of flocculants in wastewater treatment Process. Safety Environ. Protect., 92: 489-508. DOI: 10.1016/j.psep.2014.04.010

Lefebvre, E. and B. Legube, 1993. Coagulationflocculation by ferric chloride of some organic compounds in aqueous solution. Wat. Res., 27: 433-447. DOI: 10.1016/0043-1354(93)90044-I

Leonzio, G., 2017. Optimization of column distillation in a wastewater treatment plant. J. Environ. Chem. Eng., 5: 5732-5745.

DOI: $10.1016 /$ j.jece.2017.10.051
Leouifoudi, I., A. Zyad, A. Amechrouq, M.A. Oukerrou and H. Ait Mouse et al., 2014. Identification and characterisation of phenolic compounds extracted from Moroccan olive mill wastewater. Food Sci. Technol. Campinas, 34: 249-257.

DOI: $10.1590 /$ fst.2014.0051

Lesage-Meessen, L., D. Navarro, S. Maunier, J.C. Sigoillot and J. Lorquin et al., 2001. Simple phenolic content in olive oil residues as a function of extraction systems. Food Chem., 75: 501-507. DOI: 10.1016/S0308-8146(01)00227-8

Lin, Y.F. and D.J. Lee, 2013. Coagulation of natural organic matters using aluminum tridecamer (A113) with counter ions. J. Water Sustain, 3: 239-249.

Lolos, G., A. Skordilis and G. Parissakis, 1994. Polluting characteristics and lime precipitation of olive mill wastewater. J. Environ. Sci. Health A, 29: 1349-1356. DOI: $10.1080 / 10934529409376115$

Lourenço, A., J. Arnold, J.A.F. Gamelasa, O.J. Cayrec and M.G. Rasteiro, 2017. Pre-treatment of industrial olive oil mill effluent using low dosage health friendly cationic polyelectrolytes. J. Environ. Chem. Eng., 5: 6053-6060.

DOI: $10.1016 /$ j.jece.2017.11.029

Lucas, M. S. and J.A. Peres, 2009. Treatment of olive mill wastewater by a combined process: Fenton's reagent and chemical coagulation. J. Environ. Sci. Health Part A, 44: 198-205.

DOI: $10.1080 / 10934520802539889$

Maamir, W., Y. Ouahabi, S. Poncin, L. Huai-Zhi and K. Bensadok, 2017. Effect of Fenton pretreatment on anaerobic digestion of olive mill wastewater and olive mill solid waste in mesophilic conditions. Int. J. Green Energy, 14: 555-560. DOI: 10.1080/15435075.2017.1307201

Macheix, J.J., A. Fleuriet and J.A. Billo, 1990. Fruit Phenolics. 1st Edn., CRC Press Inc, Boca Raton Florida, pp: 378.

Madani, M., M. Aliabadi, B. Nasernejad, A. Kermanj Ribwar and M.Y. Kilic et al., 2015. Treatment of olive mill wastewater using physico-chemical and Fenton processes. J. Desalinat. Water Treatment, 53: 2031-2040. DOI: 10.1080/19443994.2013.860882

Markus, P.K., B. Peikert, C. Brühl, A. Dag and I. Zipori et al., 2015. Effects of olive mill wastewater on soil microarthropods and soil chemistry in two different cultivation scenarios in Israel and Palestinian Territories. Agriculture, 5: 857-878. DOI: 10.3390 /agriculture 5030857

Marques, I.P., 2001. Anaerobic digestion of olive oil mill wastewater for effluent re-use in irrigation. Desalination, 117: 233-239. DOI: 10.1016/S0011-9164(01)00224-7 
Martínez Nieto, L., G. Hodaifa, J.A. Rodríguez Vives and J.G.C. Ochando, 2011. Flocculationsedimentation combined with chemical oxidation process water. Clean Soil Air Water, 39: 949-955. DOI: $10.1002 /$ clen.201000594

Matilainen, A., E.T. Gjessing, T. Lahtinen, L. Hed and A. Bhatnagar et al., 2011. An overview of the methods used in the characterisation of Natural Organic Matter (NOM) in relation to drinking water treatment. Chemosphere, 83: 1431-1442.

DOI: 10.1016/j.chemosphere.2011.01.018

McElhatton, A. and P. Do Amaral, 2011. Novel Technologies in Food Science: Their Impact on Products, Consumer Trends and the Environment. 1st Edn., Springer-Verlag, New York, ISBN-10: 1441978801, pp: 424.

McNamara, C.J., C.C. Anastasiou, V. O'Flaherty and R. Mitchell, 2008. Bioremediation of olive mill wastewater. Int. Biodeter. Biodegr., 61: 127-134. DOI: 10.1016/j.ibiod.2007.11.003

Mekki, A., A. Dhouib, F. Aloui and S. Sayadi, 2006. Olive wastewater as an ecological fertilizer. Agron. Sustain. Dev., 26: 61-67. DOI: 10.1051/agro:2005061

Mert, B.K., T. Yonar, K.M. Yalili and K. Kestiouglu, 2010. Pre-treatment studies on olive oil mill effluent using physicochemical, Fenton and Fenton-like oxidations processes. J. Hazardous Mater., 174: 122-128. DOI: 10.1016/j.jhazmat.2009.09.025

Michael, I., A. Panagi, L.A. Ioannou, Z. Frontistis and D. Fatta-Kassinos, 2014. Utilizing solar energy for the purification of olive mill wastewater using a pilot-scale photocatalytic reactor after coagulationflocculation. Water Res. 60: 28-40. DOI: $10.1016 /$ j.watres.2014.04.032

Miguel, J. and O. Pulido, 2016. A review on the use of membrane technology and fouling control for olive mill wastewater treatment. Sci. Total Environ.

Morillo, J.A., B. Antizar-Ladislao, M. MonteolivaSanchez, A. Ramos-Cormenzana and N.J. Russell, 2009. Bioremediation and biovalorisation of olivemill wastes. Applied Microbiol. Biotechnol., 82: 25-39. DOI: 10.1007/s00253-008-1801-y

Morisot, A., 1979. Utilisation des margines par espandage. L'Olivier, 19: 8-13.

Nandy, T., S. Shastry, P.P. Pathe and S.N. Kail, 2003. Pre-treatment of currency printing ink wastewater through coagulation-flocculation process. Water Air Soil Pollut., 148: 15-30. DOI: 10.1023/A:1025454003863

Nefzaoui, A., 1991. Contribution à la rentabilité de l'oléiculture par une valirisation optimale des sousproduits, options méditerranéens.

Niaounakis, M. and C.P. Halvadakis, 2004. Olive mill wastewater management. Literature Review and patent survey, Typothito-George Dardanos, Athens, Greece.
Nigam, P., G. Armour, I.M. Banat, D. Singh and R. Marchant et al., 2000. Physical removal of textile dyes from effluents and solid-state fermentation of dye-adsorbed agricultural residues. Bioresource Technol., 74: 179-179. DOI: $10.1016 / \mathrm{S} 0960-8524(00) 00027-4$

Nissinen, T.K., I.T. Miettinen, P.J. Martikainen and T. Vartiainen, 2001. Molecular size distribution of natural organic matter in raw and drinking waters. Chemosphere, 45: 865-873.

DOI: $10.1016 / \mathrm{S} 0045-6535(01) 00103-5$

Nitro-Atomizer, 1992. Ministerio de obras publicas y transportes-confederacion hidrografica del Guadalquivir. Plan de puesta en marcha de plantas experimentales de depuracion $\mathrm{y}$ eliminacion de alpechines en las cuencas de los rios Guadalquivir y Guadalete-Evaluacion de la experiencia. Yuly Sevilla.

Nozaic, D.J., S.D. Freese and P. Thompson, 2001. Longterm experience in the use of polymeric coagulants at Umgeni Water. Water Sci. Technol., 1: 43-50. DOI: 10.2166/ws.2001.0006

Ntougias, S., F. Gaitis, P. Katsaris, S. Skoulika and N. Iliopoulos et al., 2013. The effects of olives harvest period and production year on olive mill wastewater properties-evaluation of Pleurotus strains as bioindicators of the effluent's toxicity. Chemosphere, 92: 399-405.

DOI: 10.1016/j.chemosphere.2013.01.033

Obied, H.K., M.S. Allen, D.R. Bedgood, P.D. Prenzler and K. Robards et al., 2005. Bioactivity and analysis of biophenols recovered from olive mill waste. J. Agric. Food Chem., 53: 823-837.

DOI: $10.1021 / \mathrm{jf0} 48569 \mathrm{x}$

Ochando-Pulido, J.M., M. Stoller, L. Di Palma and A. Martinez-Ferez, 2014. Threshold performance of a spiral-wound reverse osmosis membrane in the treatment of olive mill effluents from two-phase and three-phase extraction processes. Chem. Eng. Process. Intensif., 83: 64-70. DOI: $10.1016 /$ j.cep.2014.07.006

Olori, L., S. Fulvio and P. Morgia, 1990. Acque di vegetazione. Le problematiche ambientalie gli aspetti igienico. Inquinamento, 1: 40-46.

Otlesa, S. and I. Seleka, 2012. Treatment of olive mill wastewater and the use of polyphenols obtained after treatment. Int. J. Food Stud., 1: 85-100. DOI: $10.7455 / \mathrm{ijfs} / 1.1 .2012 . \mathrm{a} 9$

Ouzounidou, G., G.I. Zervakis and F. Gaitis, 2010. Raw and microbiologically detoxified olive mill waste and their impact on plant growth. Terrestrial Aquatic Environ. Toxicol., 4: 21-38.

Papadaki, E., M.Z. Tsimidou and F. Mantzouridou, 2018. Changes in phenolic compounds and phytotoxicity of the spanish-style green olive processing wastewaters by aspergillus niger B60. J. Agric. Food Chem., 66: 4891-4901.

DOI: 10.1021/acs.jafc.8b00918 
Papaphilippou, P.C., C. Yiannapas, M. Politi, V.M. Daskalaki and C. Michael et al., 2013. Sequential coagulation-flocculation, solvent extraction and photo-Fenton oxidation for the valorization and treatment of olive mill effluent. Chem. Eng. J., 224: 82-88. DOI: 10.1016/j.cej.2012.11.047

Paraskeva, P. and E. Diamadopoulos, 2006. Technologies for Olive Mill Wastewater (OMW) treatment: A review. J. Chem. Technol. Biotechnol., 8: 1475-1485. DOI: $10.1002 /$ jctb. 1553

Pathak, P.D. and S.A. Mandavgane, 2015. Preparation and characterization of raw and carbon from banana peel by microwave activation: Application in citric acid adsorption. J. Environ. Chem. Eng., 3: 2435-2447. DOI: $10.1016 /$ j.jece.2015.08.023

Pearson, J., F. Lu and K. Gandhi, 2004. Disposal of woul scouring sludge by composting. AUTEX Res. J., 4: 147-156.

Pelendridou, K., K.M. Michailides, D.P. Zagklis, A.G. Tekerlekopoulou and C.A. Paraskeva et al., 2014. Treatment of olive mill wastewater using a coagulation-flocculation process either as a single step or as post $\square$ treatment after aerobic biological treatment. Chem. Technol. Biotechnol., 89: 18661874. DOI: $10.1002 /$ jctb.4269

Pernitsky, D.J. and J.K. Edzwald, 2006. Selection of alum and polyaluminum coagulants: Principles and applications. J. Water Supply Res. Technol., 55: 121-141. DOI: 10.2166/aqua.2006.062

Polizzi, S., E. Pira, M. Ferrara, M. Bugiani and A. Papaleo et al., 2002. Neuro toxic effects of aluminium among Foundry workers and Alzheimer's disease. Neurotoxicology, 23: 761-774. DOI: $10.1016 / \mathrm{S} 0161-813 \mathrm{X}(02) 00097-9$

Pourrezaei, P., P. Drzewicz, Y. Wang, M. Gamal El-Din and L.A. Perez-Estrada et al., 2011. The impact of metallic coagulants on the removal of organic compounds from oil sands process-affected water. Environ. Sci. Technol., 45: 8452-8459.

DOI: $10.1021 / \mathrm{es} 201498 \mathrm{v}$

Qin, J.J., M.H. Oo, K.A. Kekre, F. Knops and P. Miller, 2006. Impact of coagulation $\mathrm{pH}$ on enhanced removal of natural organic matter in treatment of reservoir water. Sep. Purif. Technol., 49: 295-298. DOI: 10.1016/j.seppur.2005.09.016

Quaratino, D., A. D'Annibale, F. Federici, C.F. Cereti and F. Rossini et al., 2007. Enzyme and fungal treatments and a combination thereof reduce olive mill wastewater phytotoxicity on Zea mays L. Seeds. Chemosphere, 66: 1627-1633.

DOI: 10.1016/j.chemosphere.2006.07.092

Radoiu, M.T., D.I. Martin, I. Calinescu and H. Iovu, 2004. Preparation of polyelectrolytes for wastewater treatment. J. Hazard. Mater., 106: 27-37.

DOI: $10.1016 /$ j.jhazmat.2003.08.014
Ragazzi, E. and G. Veronese, 1973. Research on the phenolic components of olive oils. Riv. Ital. Sost. Grasse., 50: 443-452.

Razali, M.A.A., Z. Ahmad, M.S.B. Ahmad and A. Ariffin, 2011. Treatment of pulp and paper mill wastewater with various molecular weight of polyDADMAC induced flocculation. Chem. Eng. J., 166: 529-535. DOI: 10.1016/j.cej.2010.11.011

Renault, F., B. Sancey, P.M. Badot and G. Crini, 2009. Chitosan for coagulation/flocculation processesan eco-friendly approach. Eur. Polymer J., 45: 1337-1348.

DOI: 10.1016/j.eurpolymj.2008.12.027

Rezeg, A. and S. Achour, 2005. Elimination d'acides organiques aromatiques par coagulation-floculation au sulfate d'aluminium. Larhyss J., 04: 141-152.

Rizzo, L., G. Lofrano, M. Grassi and V. Belgiorno, 2008. Pretreatment of olive mill wastewater by chitosan coagulation and advanced oxidation processes. Sep. Purif. Technol., 63: 648-653. DOI: 10.1016/j.seppur.2008.07.003

Rodis, P.S., V.T. Karathanos and A. Mantzavinou, 2002. Partitioning of olive oil antioxidants between oil and water phases. J. Agric. Food Chem., 50: 596-601. DOI: $10.1021 / \mathrm{jf0} 10864 \mathrm{j}$

Rodríguez, G., A. Lama, M. Trujillo, J.L. Espartero and J. Fernández-Bolaños, 2009. Isolation of a powerful antioxidant from Olea europaea fruit-mill waste: 3,4- dihydroxyphenylglycol. LWT Food Sci. Technol., 42: 483-490.

DOI: $10.1016 /$ j.lwt.2008.08.015

Roig, A., M.L. Cayuela and M.A. Sanchez-Monedero, 2006. An overview on olive mill wastes and their valorization methods. Waste Manage., 26: 960-969. DOI: 10.1016/j.wasman.2005.07.024

Rozzi, A. and F. Malpeli, 1996. Treatment and disposal of olive mill effluents. Int. Biodeterior. Biodegrad., 38: 135-144. DOI: 10.1016/S0964-8305(96)00042-X

Ruggeri, B., M. Bernardi, D. Fino and G. Mancini, 2015. The selection of pretreatment options for Anaerobic Digestion (AD): A case study in olive oil waste production. Chem. Eng. J., 259: 630-639. DOI: 10.1016/j.cej.2014.08.035

Sampaio, M.A., M.R. Gonçalves and I.P. Marques, 2011. Anaerobic digestion challenge of raw olive mill wastewater. Bioresour. Technol., 102: 10810-10818. DOI: $10.1016 /$ j.biortech.2011.09.001

Sanches, S., M.C. Fraga, N.A. Silva, P. Nunes and J.G. Crespo et al., 2016. Pilot scale nanofiltration treatment of olive mill wastewater: A technical and economical evaluation. Environ. Sci. Pollut. Res.

Sarika, R., D. Mantzavinos and N. Kalogerakis, 2005. Treatment of olive mill effluents. Part II: Complete removal of solids by direct flocculation with polyelectrolytes. Environ. Int., 31: 297-304. DOI: $10.1016 /$ j.envint.2004.10.006 
Sathishkumar, M., K. Vijayaraghavan, A.R. Binupriya, M. Stephan and J.G. AChoi et al., 2008. Porogen effect on characteristics of banana pith carbon and the sorption of dichlorophenols. J. Colloid Interf. Sci., 320: 22-29. DOI: 10.1016/j.jcis.2007.12.011

Sbai, G. and M. Loukili, 2015. Traitement des margines par un procède couplant la coagulation floculation et la voie électrochimique. Eur. Scientific J., 11: 158-169.

Sellami, F., R. Jarboui, S. Hachicha, K Medhioub and E. Ammar, 2008. Composting of oil exhausted olivecake, poultry manure and industrial residues of agrofood activity for soil amendment. Bioresource Technol., 99: 1177-1188. DOI: 10.1016/j.biortech.2007.02.018

Sharp, E., P. Jarvis, S.A. Parsons and B. Jefferson, 2006. Impact of fractional character on the coagulation of NOM. Colloid Surf. A Physicochem Eng. Asp., 286: 104-111.

Sillanpaa, M., M.C. Ncibi, A. Matilainen and M. Vepsalainen, 2018. Removal of natural organic matter in drinking water treatment by coagulation: A comprehensive review. Chemosphere, 190: 54-71. DOI: 10.1016/j.chemosphere.2017.09.113

Soler-Rivas, C., J.C. Espín and H.J. Wichers, 2000. Oleuropein and related compounds. J. Sci. Food Agric., 80: 1013-1023.

DOI:

10.1002/(SICI)1097-

0010(20000515)80:7<1013::AID-

JSFA571>3.0.CO;2-C

Speltini, A., F. Maraschi, M. Sturini, V. Caratto and M. Ferretti et al., 2016. Sorbents coupled to solar light $\mathrm{TiO}_{2}$-based photocatalysts for olive mill wastewater treatment. Int. J. Photoenergy. DOI: $10.1155 / 2016 / 8793841$

Stoller, M. and A. Chianese, 2006. Optimization of membrane batch processes by means of the critical flux theory. Desalination, 191: 62-70. DOI: $10.1016 /$ j.desal.2005.07.021

Stoller, M. and A. Chianese, 2006. Technical optimization of a batch olive wash wastewater treatment membrane plant. Desalination, 200: 734-736.

DOI: $10.1016 /$ j.desal.2006.03.501

Stoller, M. and A. Chianese, 2007. Influence of the adopted pretreatment process on the critical flux value of batch membrane processes. Ind. Eng. Chem. Res., 46: 2249-2253.

DOI: $10.1021 / \mathrm{ie} 060964 \mathrm{k}$

Stoller, M., 2009. On the effect of flocculation as pretreatment process and particle size distribution for membrane fouling reduction. Desalination, 240: 209-217. DOI: 10.1016/j.desal.2007.12.042

Taccari, M. and M. Ciani, 2011. Use of Pichia fermentans and Candida sp. Strains for the biological treatment of stored olive mill wastewater. Biotechnol. Lett., 33: 2385-2390.

DOI: $10.1007 / \mathrm{s} 10529-011-0708-3$
Tekerlekopoulou, A.G., C.S. Akratos and D.V. Vayenas, 2017. Integrated Biological Treatment of Olive Mill Waste Combining Aerobic Biological Treatment, Constructed Wetlands and Composting. In: Olive Mill Waste: Recent Advances for Sustainable Management, Galanakis, C.M. (Ed.), Elsevier Science, Saint Louis, ISBN-10: 0128053143, pp: 139-159.

DOI: 10.1016/B978-0-12-805314-0.00007-8

Tipping, E., M.M. Reddy and M.A. Hurley, 1990. Modelling electrostatic and heterogeneity effects on proton dissociation from humic substances. Environ. Sci. Technol., 24: 1700-1705.

DOI: $10.1021 / \mathrm{es} 00081 \mathrm{a} 012$

Torres, M.M. and D.M. Maestri, 2006. The effects of genotype and extraction methods on chemical composition of virgin olive oils from Traslasierra Valley (Cordoba, Argentina). Food Chem., 96: 507-511. DOI: 10.1016/j.foodchem.2005.03.003

Tsagaraki, E.H., N. Lazarides and K.B. Petrotos, 2007. Olive mill wastewater. Utilisation of by-products and treatment of waste in the food industry. Springer.

Turano, E., S. Curcio, M.G. De Paola, V. Calabro and G., Iorio, 2002. An integrated centrifugationultra ltration system in the treatment of olive mill wastewater. J. Membrane Sci., 209: 519-531. DOI: 10.1016/S0376-7388(02)00369-1

Tzoupanos, N.D. and A.I. Zouboulis, 2008. Coagulationflocculation processes in water/wastewater treatment: The application of new generation of chemical reagents. Proceedings of the 6th IASME/WSEAS International Conference on Heat Transfer, Thermal Engineering and Environment, (TEE' 08).

Van der Bruggen, B., L. Lejon and C. Vandecasteele, 2003. Reuse, treatment and discharge of the concentrate of pressure-driven membrane processes. Environ. Sci. Technol., 37: 3733-3738. DOI: $10.1021 / \mathrm{es} 0201754$

Visioli, F., A. Poli and C. Gall, 2002. Antioxidant and other biological activities of phenols from olives and olive oil. Med. Res. Rev., 22: 65-75. DOI: $10.1002 / \mathrm{med} .1028$

Vlyssides, A.G., M. Loizides and P.K. Karlis, 2004. Integrated strategic approach for reusing olive oil extraction by-products. J. Cleaner Product., 12: 603-611. DOI: 10.1016/S0959-6526(03)00078-7

Wais-Mossa, M.T. and M. Mazet, 1991. Influence des sels minéraux sur l'adsorption des acides humiques sur flocs d'hydroxydes de fer préformés. Environ. Technol., 12: 725-730. DOI: $10.1080 / 09593339109385062$

Wang, J., W. Xu, J. Xu, D. Wei and H. Feng et al., 2016. Effect of aluminum speciation and $\mathrm{pH}$ on in-line coagulation/diatomite microfiltration process: Correlations between aggregate characteristics and membrane fouling. J. Molec. Liq., 224: 492-501. DOI: 10.1016/j.molliq.2016.10.015 
Wang, Z., J. Nan, M. Yao, Y. Yang and X. Zhang, 2017. Insight into the combined coagulation-ultrafiltration process: The role of Al species of polyaluminum chlorides. J. Memb. Sci., 529: 80-86.

DOI: 10.1016/j.memsci.2017.01.061

Ward, R.J.S., C.R. McCrohan and K.N. White, 2006. In fluence of aqueous aluminium on the immune system of the fresh water cray fish Pacifasticus leniusculus. Aquat. Toxicol., 77: 222-228. DOI: $10.1016 /$ j.aquatox.2005.12.006

Wei, Y., X. Dong, A. Ding and D. Xie, 2016. Characterization and coagulation flocculation behavior of an inorganic polymer coagulant polyferric-zinc-sulfate. J. Taiwan Inst. Chem. Eng., 58: 351-356. DOI: 10.1016/j.jtice.2015.06.004

Xiao, F., P. Yi, X.R. Pan, B.J. Zhang and C. Lee, 2010. Comparative study of the effects of experimental variables on growth rates of aluminum and iron hydroxide flocs during coagulation and their structural characteristics. Desalination, 250: 902-907. DOI: 10.1016/j.desal.2008.12.050

Yaakoubi, A., A. Chahlaoui, M. Rahmani, M. Elyachioui and Y. Oulhote, 2010. Effet de l'épandage des margines sur la microflore du sol. Agro Solut., 20: 35-43.

Yalılı Kılıç, M., T. Yonar and K. Kestioglu, 2013. Pilotscale treatment of olive oil mill wastewater by physicochemical and advanced oxidation processes. Environ. Technol., 34: 1521-1531. DOI: $10.1080 / 09593330.2012 .758663$

Yangui, A. and M. Abderrabba, 2018. Towards a high yield recovery of polyphenols from olive mill wastewater on activated carbon coated with milk proteins: Experimental design and antioxidant activity. Food Chem., 262: 102-109.

DOI: 10.1016/j.foodchem.2018.04.091

Yay, A.S.E., H.V. Oral, T.T. Onay and O. Yenigün, 2012. A study on olive oil mill wastewater management in Turkey: A questionnaire and experimental approach. Resour. Conserv. Recycl., 60: 64-71. DOI: 10.1016/j.resconrec.2011.11.009

Yazdanbakhsh, A., F. Mehdipour, A. Eslami, H. Sharifi Maleksari and F. Ghanbari, 2015. The combination of coagulation, acid cracking and Fenton-like processes for olive oil mill wastewater treatment: Phytotoxicity reduction and biodegradability augmentation. Water Sci. Technol., 71: 1097-1105.
Zagklis, D.P., A.I. Vavouraki, M.E. Kornaros and C.A. Paraskeva, 2015. Purification of olive mill wastewater phenols through membrane filtration and resin adsorption/desorption. J. Hazard. Mater., 285: 69-76.

DOI: $10.1016 /$ j.jhazmat.2014.11.038

Zahrima, A.Y., Z.D. Dextera, C.G. Josephb and N. Hilal, 2017. Effective coagulation-flocculation treatment of highly polluted palm oil mill biogas plant wastewater using dual coagulants: Decolourisation, kinetics and phytotoxicity studies. J. Water Process Eng., 16: 258-269.

DOI: 10.1016/j.jwpe.2017.02.005

Zanjari, B. and A. Nejmeddine, 2001. Impact of spreading olive mill wastewater on soil characteristics: Laboratory experiments, INRA, EDP Sciences. Agronomie, 21: 749-755.

DOI: 10.1051/agro:2001163

Zhang, S., S.G. Xie and X.J. Zhang, 2003. The study progress of the control of natural organic matter in raw water by enhanced coagulation (in Chinese). Tech Equip. Environ. Pollut. Control, 4: 19-22.

Zheng, H., G. Zhu, S. Jiang, T. Tshukudu and X. Xiang et al., 2011. Comparison of a novel polytitanium chloride coagulant with polyaluminium chloride: Coagulation performance and floc characteristics. Desalination, 269: 148-156. DOI: 10.1016/j.desal.2010.10.054

Zhu, B., D.A. Clifford and S. Chellam, 2005. Comparison of electrocoagulation and chemical coagulation pre-treatment for enhanced virus removal using microfiltration. Water Research , 39: 3098-3108.

Zouboulis, A.I., P.A. Moussas and F. Vasilakou, 2008. Polyferric sulphate: Preparation, characterisation and application in coagulation experiments. J. Hazard. Mater., 155: 459-468.

DOI: $10.1016 /$ j.jhazmat.2007.11.108

Zümriye, A. and Y. Jülide, 2001. A comparative adsorption/biosorption study of mono-chlorinated phenols Phenols onto various sorbents. Waste Manage., 21: 695-702.

DOI: $10.1016 / \mathrm{S} 0956-053 \mathrm{X}(01) 00006-\mathrm{X}$ 